\title{
Analysis on Target Safety Level for Egress from a Fire Room and a Fire Floor in Typical Office Buildings
}

\author{
Masayuki Mizuno $^{1}$, Kazunori Harada ${ }^{2}$ and Takao Wakamatsu ${ }^{1}$ \\ ${ }^{1}$ Center for Fire Science and Technology, Tokyo University of Science, Japan \\ ${ }^{2}$ Department of Architecture and Architectural Systems, Graduate School of Engineering, \\ Kyoto University, Japan
}

\begin{abstract}
The Japanese Ministry of Construction's Notification 1441 (2000) on "Verification Method for Egress Safety from a Fire Floor" is composed of a set of prescribed characteristic input values for fire load density, occupant density, etc., coupled with a set of simplified formulae to calculate fire and evacuation behavior. The nominal egress time margin is calculated by combining these values and formulae with building design variables, such as room area and ceiling height. To clarify the degree of safety implemented in the verification method, the stochastic variability in input values and uncertainties in calculation formulae have been examined. Based on existing research and survey results, variability and uncertainty are expressed in terms of probability density functions.

The target levels of egress from a fire room and a fire floor were also discussed in this study. The calculation method was analyzed using the methods of Reliability Engineering. The Limit State Function was selected as the difference between the nominal time margin of egress safety and the actual, stochastic time margin of egress safety. By examining the safety level of Limit State Function, the Target Safety Index and the Acceptable Probabity of Failure implied in the Verification Method is clarified for typical office building in Japan.

This work has clarified that: (1) Two variables which contain inevitable stochastic variation (Fire Load Density and Occupant Density) are recognized as Type A variables, and six variables which contain uncertainties due to the incompleteness of the prediction method (Walking Velocity, Specific Flow Rate, Time to Start the Evacuation, Fire Growth Rate over combustible contents, Fire Growth Rate over lining materials, and Smoke Filling Time) are recognized as Type B variables. (2) The coefficients of variation are large in both Type A and Type B variables, ranging from 13 to $235 \%$. There is a need to reduce the uncertainties associated with Type B variables. (3) The Partial Safety Factors vary in the range of -0.45 to 4.97 . (4) The implied safety index of the calculation method is in the range of 1 to 3 depending on the method of smoke control and floor area on the condition of egress from a fire room, and in the range of 2 to 3 it is fairly independent on the method of smoke control and floor area on the condition of egress from a fire floor. (5) In comparison with Type A variability, the effect of Type B uncertainties (prediction error) is not negligible. (6) Possible combination of partial safety factors are proposed
\end{abstract}


by $0.2,2-6,0.9$ for fire load density, escape start time and smoke filling time on the condition of egress from a fire room for typical office buildings with single side corridor in Japan, and by $0.7,4.8,2.6$ and 0.9 for fire load density, escape start time, fire growth rate and smoke filling time on the condition of egress from a fire floor.

Keywords : Reliability engineering, Egress safety, Target safety index, Acceptable probability of failure, Partial safety factor, Probability density functions, Monte-Carlo method

\section{INTRODUCTION}

In the year 2000, the shift of Building Standard Law of Japan towards performance-based codes has lead to the enactment of two notifications: "Verification Method for Egress Safety from a Fire Floor" and "Verification Method for Egress Safety from a Building".[1] The Verification Method for Egress Safety from a Fire Floor concerns safe evacuation from a room or floor on fire, and the Verification Method for Egress Safety from a Fire Building concerns safe evacuation from the building on fire. These methods are now being applied to many building design cases, as conforming to these notifications will allow some of the prescriptive codes (smoke control systems, restrictions on walking distances for evacuation, total required width of the escape stairs, etc.) to be excluded from the application, effectively producing advantages such as increased flexibility in building design and reduced construction cost.

The calculation system in these notifications is composed of a set of explicit "Characteristic Input Values" (prescribed input values) and simplified formulae, thus enabling the decision of the approval/disapproval (margin of safety) of a building design using a seemingly deterministic method. There are variables, such as the Occupant Density and the Fuel Load Density, that naturally contain variability within them. Characteristic Input Values are defined for these variables, so that each of them will include an appropriate percentile value in consideration of the variation. This also implies that a certain degree of Safety Factor is implicitly inherent within a Characteristic Input Value. Simplified formulae are used to predict the evacuation behavior or the characteristics of fire or smoke. The formulae are derived by introducing a certain degree of Safety Factors to the achievements of the theoretical and/or experimental research. Therefore, the calculation system prescribed in these notifications requires a safety performance above a certain level, which is realized through the combination of Safety Factors concealed within the characteristic input values and the prediction formulae. The overall safety level assured by the calculation system is conceived as a socially acceptable risk, however, there is no prescription on a specific level of target.

As seen in Critical State Design Method [2], a new design method is being proposed in the field of structural design of buildings. In this method, the structural design is performed to keep the Probability of Failure (Exceedance) below an acceptable level 
with the variations of the input values treated as probability distributions. In the field of fire safety, for example, Magnusson et al.[3] proposed a method of expressing the safety level quantitatively by applying the method of risk uncertainty analysis, and Frantzich [4] used this method to evaluate the safety of multiple building plans through relative comparison of risks.

It is considered necessary to clarify the target level of safety (Acceptable Probability of Failure) in order to design buildings explicitly according to performance-based methods. Therefore, in this study, the method of Reliability Engineering [5] is introduced to analyze the Safety Factor minimally guaranteed by the "Verification Method for Egress Safety from a Fire Floor" (hereafter referred to as the "Verification Method") for designs in conformance to the Verification Method. The purpose of this is to clarify the level of safety that the Verification Method provides (in other words, the target level of safety in the Verification Method). As the first step, the inevitable variability of the Characteristic Input Values and the precision of the prediction formulae in the Verification Method are estimated from the existing results of experiments and surveys, and expressed in Probability Density Function ( $p d f)$. Also, the Partial Safety Factors included in the Characteristic Input Values and the formulae prescribed in the Verification Method (hereafter referred to as the "prescribed values of the Verification Method") are clarified.

As the next step, the minimal safety level obtained in the case that the design meets the requirements of the Verification Method is analyzed for both room evacuation and floor evacuation. The method of Reliability Engineering is used in the analysis. The variables that are considered as design values in the Verification Method can be determined freely by the designer. Then, Monte-Carlo simulation is performed on the other "Stochastic Variables" that possess variation caused by intrinsic and inevitable variability or prediction errors, and the distribution of the finally obtained Egress Time Margin $t_{\text {margin }}$ is analyzed. Monte-Carlo simulation uses stochastic input (input based on probability) according to the Probability Density Function ( $p d f)$. In the future, if the Target Safety Level requested in the Verification Method prescribed in the notification is clarified, it will open a door to the possibility of a rational approach towards fire safety design based on explicit setting of Target Safety Level.

It is also shown in this paper through the evaluation of Partial Safety Factors corresponding to the prescribed values of the Verification Method that the Partial Safety Factors are fairly independent of the variation coefficients. In order to achieve a well-balanced calculation method, it is considered that the prescribed values of the Verification Method should be brought as close as possible to the Most Probable Failure Point (hereafter referred to as MPFP) - the point where the frequencies of occurrence becomes highest out of the unsafe states (combination of Stochastic Variables). For this purpose, the degree of influence (sensitivity) of the variation of the each Stochastic Variables causes the variation of the Egress Time Margin is calculated, and the Partial Safety Factors corresponding to the Most Probable Failure Point are determined for the variables that exhibited high sensitivity. Therefore, using this method, it is theoretically 
possible to find out the relevant combination of the explicit input values close to reality (close to the mode of the probability distribution) while keeping the Target Safety Level constant.

The Characteristic Input Values and the formulae prescribed in the Verification Method can be categorized essentially according to the usage of the rooms and buildings. Therefore, using such categorization, the data corresponding to the category of office use are selected to be used in the survey of variability and precision of prediction, as there was a relatively abundant set of data available for this category. By breaking the data on the existing office buildings with single side corridor in Japan down into patterns, several combinations of design values were defined as typical office buildings. These were assigned as the objects to be analyzed on of the level of Target Egress Safety and the MPFP. Therefore, the scope of the Partial Safety Factors of the Stochastic Variables proposed in this study is restricted to the specific combinations of data for above-mentioned typical office buildings.

\section{ANALYSIS OFTHE VERIFICATION METHOD FOR EGRESS SAFETY FROM A FIRE FLOOR IN THE ASPECT OF RELIABILITY ENGINEERING}

As illustrated in Figure 1, the basic concept of the Verification Method is to confirm that the occupants are able to evacuate safely from the building via a designated egress route in the case a fire breaks out within the room. As Equation (1) shows, in order to conform to the Verification Method, it is requested that the Time to Evacuation $t_{e}$ is shorter than the Time Limit of Evacuation (the allowance of time $t_{S}$ until smoke fills the entire egress route). As given in Equation (2), the Time to Evacuation $t_{e}$ is derived as the sum of the time interval before starting evacuation $\left(t_{\text {start }}\right)$, time to walk from the most distant position to the exit (travel $)$, and the time to pass through the bottlenecks on the egress route $\left(t_{\text {queue }}\right)$. In Room Evacuation, the Smoke Filling Time $\left(t_{S}\right)$ is defined as the time takan for the smoke in the fire room to descend to a height of $1.8 \mathrm{~m}$. In Floor Evacuation, $t_{S}$ is derived as the sum of the time required for the layer of smoke in the fire room to descend to the height at which the smoke will propagate to the contiguous corridor through the door and the time taken for the smoke that has reached the corridor to come down to a height of $1.8 \mathrm{~m}$.

$$
\begin{aligned}
t_{e} & \leq t_{s} \\
t_{e} & =t_{\text {start }}+t_{\text {travel }}+t_{\text {queue }} \\
& =f\left(A_{\text {area }}, A_{\text {co }}, A_{\text {load }}, A_{\text {st }}, B_{\text {neck }}, B_{\text {load }}, B_{\text {room }}, B_{\text {neck }}, l_{l}, a_{n}, N, p, q_{l}, v\right) \\
t_{s} & =f\left(A_{\text {room }}, H_{\text {room }}, w, q_{l}, \alpha_{m}\right)
\end{aligned}
$$


Taking the difference between the left and the right hand side terms in Equation (1) and defining this value as Egress Time Margin $\left(t_{\text {margin }}\right)$, the condition conforms to the Verification Method can be described as follows:

$$
t_{\text {margin }}=t_{s}-t_{e} \geq 0
$$

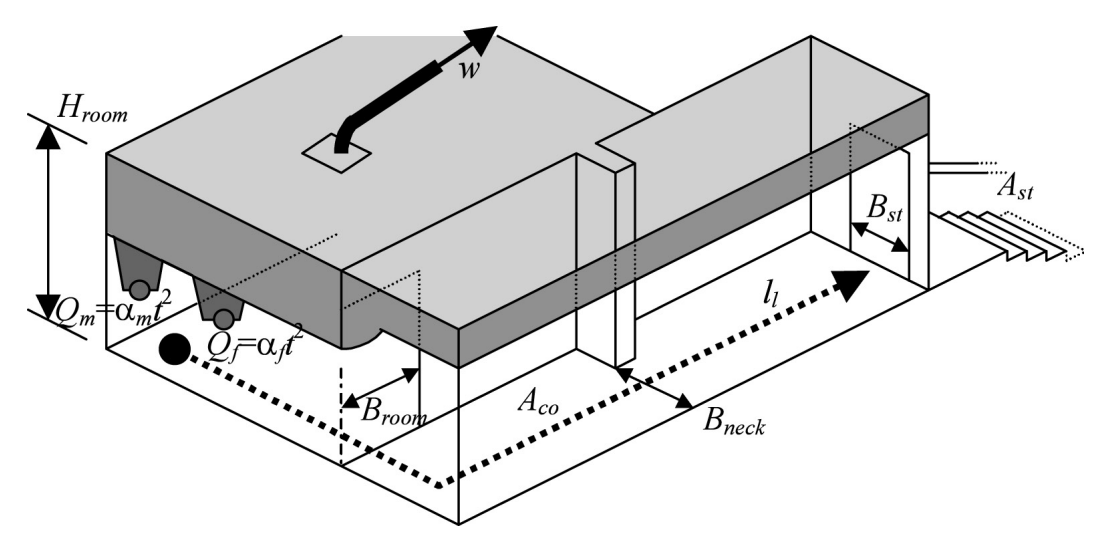

Figure 1 Basic Concept of the Verification Method for Egress Safety from a Fire Floor

In the Verification Method, the Egress Time Margin $t_{\text {margin }}$ can be calculated deterministically by using the prescribed values for the input of values such as Occupant Density and Fuel Load Density. As the actual fire incidents show, defects and failures of fire-prevention equipment (e.g. fire doors, smoke control system, etc.) have often led to disasters in the past. The Verification Method is constructed under the assumption that fire-prevention equipment will provide its effect expected. However, in reality, the Egress Time Margin cannot always be given as a deterministic value as there will be some uncertainty inherent within the value. We will focus in this study on quantifying the uncertainty in the Egress Time Margin produced by the uncertainty of the input variables. It is considered that the functional reliability of the individual facilities will be guaranteed through other means, and will not be dealt with in the scope of this study [Note 1].

When Equation (4) is calculated taking the uncertainty of the input values into account, the Egress Time Margin will take a negative value with a certain probability, thus the evacuation will fail. Therefore, by quantifying the variation in the input values and grasping the magnitude of variation of the Egress Time Margin, the Level of Safety requested by the Verification Method can be provided in terms of Probability of Failure (the probability that the Egress Time Margin becomes negative).

The input variables of the Verification Method, as illustrated in Figure 2, can be categorized into two types: those that are determined as definite design values (the floor area, the door widths, etc.) and those that are uncertain. The input variables with uncertainty are further divided into two types: those with a characteristic that substantial variations of the values are inevitable $\left(p\right.$ and $\left.q_{l}\right)$; and those that contain 
uncertainties, such as prediction error $\left(v, N, t_{\text {start }}, \alpha_{f}, \alpha_{m}, t_{s}\right)$. In Reliability Engineering, the first type is called a "Type A" variable, and the second type is called a "Type B" variable. The variation of value in a Type A variable cannot be reduced; therefore, a certain degree of Safety Factor must always be applied regardless of the type of design method adopted. In contrast, the uncertainty in a Type B variable might be reduced by the future advancement of prediction technique. Type A and Type B variables are called the "stochastic" variables.

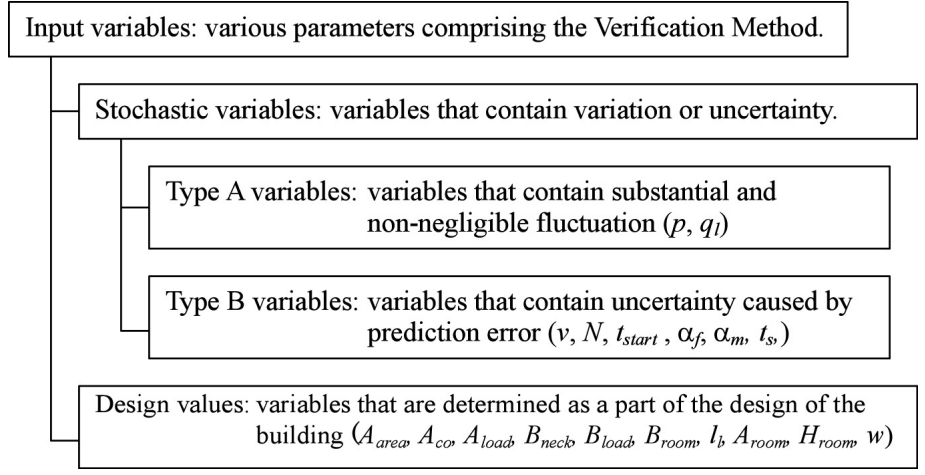

Figure 2 Categorizing of the Input Variables based on Reliability Engineering

\section{SERVEYS ON THE VARIATION OF THE STOCHASTIC VARIABLES}

In order to grasp the actual situation of the variation of the variables categorized as Type A or Type B in the previous section, data were collected from a number of existing references and attempts were made to express them using Probability Density Functions $(p d f)$. The result is presented in the following subsections:

\subsection{Type A Variable}

The two stochastic variables categorized as Type A are Occupant Density $(p)$ and Fuel Load Density $(q)$. In the Verification Method, "Characteristic Input Values" are defined according to the usage of the room. An office was selected as the usage of the room, as, for this purpose, a more or less complete set of data was available in the existing references, and the $p d f \mathrm{~s}$ were derived from the data collected from the existing results of surveys.

\subsubsection{Occupant Density ( $p$ ) [persons/ $\mathrm{m}^{2}$ ]}

The previous works on the Occupant Density include a study on the percentage of the persons present inside the room (depending on the time of the day) out of all the persons registered as the occupants of the room ${ }^{6}$, and the studies that provide the number of registered persons per floor area of the room, analyzed from the aspects of occupation, 
scale of the building, and the room area[7-9]. The result of the first study provided that the number of occupants of the room during office hours would be somewhere around $95 \%$ of the total registered number of persons. Considering the result, in the latter works, the Occupant Density was defined by dividing the registered number of persons by the area of the floor. In this study, the surveys results on the floor spaces used mainly for clerical work (hereafter referred to as "office for clerical job") were selected to provide a histogram [Note 2] shown in Figure 3.

The mean value was 0.122 [persons $/ \mathrm{m}^{2}$ ], and the standard deviation gave 0.07 [persons $/ \mathrm{m}^{2}$ ]. A total of 393 samples were obtained, and it is assumed from the shape of the histogram, that the distribution follows a lognormal distribution expressed as Equation (5):

$$
p=\log \operatorname{Normal}(0.122,0.07)\left[\text { persons } / \mathrm{m}^{2}\right]
$$

The prescribed values of the Verification Method are 0.125 [persons $/ \mathrm{m}^{2}$ ], which coincides well with the mean value.

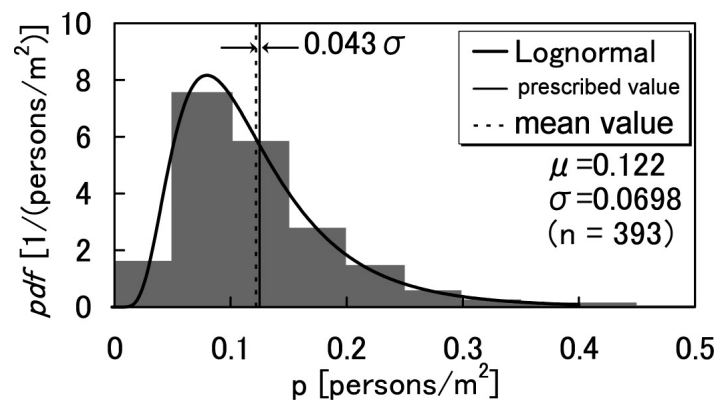

Figure 3 Result of the Study on the Occupant Density $p$ [persons $/ \mathrm{m}^{2}$ ] and Probability Density Function (Office for Clerical Job)

\subsubsection{Fuel Load Density $\left(q_{l}\right)\left[M J / m^{2}\right]$}

In many of the existing studies concerning the fire load at the office room, the results are grouped into two types: one for clerical jobs (management function etc.), and the other for technical jobs (designing, etc.). This approach is adopted in this study, and the results of the research[10,11] were sorted into two types of office jobs.

Figure 4 shows the result of the research on offices for clerical jobs. Here the mean value is $14.1 \mathrm{~kg} / \mathrm{m}^{2}\left(235 \mathrm{MJ} / \mathrm{m}^{2}\right)$ and the standard deviation is $4.1 \mathrm{~kg} / \mathrm{m}^{2}\left(65.4 \mathrm{MJ} / \mathrm{m}^{2}\right)$. The data was insufficient to provide an assumption on the shape of the distribution curve, however, since it is widely accepted that the live load for structural design takes a lognormal distribution[12], the following equation was adopted.

$$
q_{l}=\log \operatorname{Normal}(235,65.4)\left[\mathrm{MJ} / \mathrm{m}^{2}\right]
$$

The Characteristic Input Value used in the Verification Method is $35 \mathrm{~kg} / \mathrm{m}^{2}\left(560 \mathrm{MJ} / \mathrm{m}^{2}\right)$, which is fairly large compared with the range of variation. 


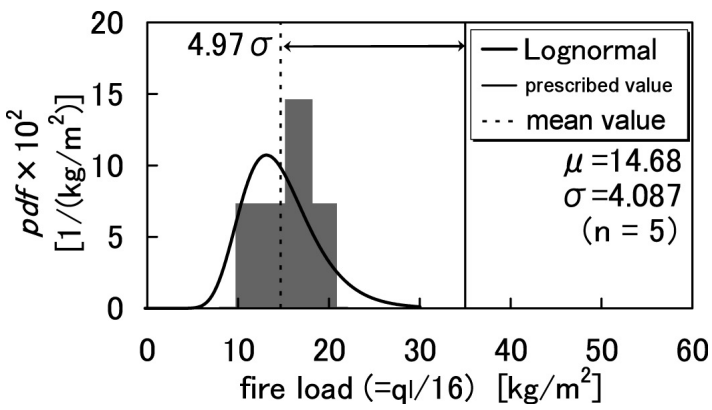

Figure 4 Result of the Study on Fire Load $\left(=q_{1} / 16[\mathrm{MJ} / \mathrm{kg}]\right)$ and Probability Density Function (Office for Clerical Job)

\subsection{Type B Variables}

It is considered that a Type B variable, like in the case with a Type A variable, will have a dependency on the characteristics of the usage of the room, therefore, the results for offices are gathered in this study.

There are 6 variables that are recognized as Type B variables: Walking Velocity $v$, Flow Rate $N$, time interval before starting evacuation $t_{\text {start }}$, Fire Growth Rate of the Fuel Load $\alpha_{f}$, Fire Growth Rate of the interior finishing material $\alpha_{m}$ and Smoke Filling Time $t_{s}$. Out of these variables, the time interval before starting evacuation $t_{\text {start }}$, Fire Growth Rate of the Fuel Load $\alpha_{f}$ and the Smoke Filling Time $t_{S}$ are not the explicit numerical variation, rather, they are regarded as the variation of errors in the prediction formulae. In quantifying these variables, the Compensating Rate of the prediction formulae is defined as follows:

$$
f_{\text {var }}=\frac{(\text { value obtained in experiments or surveys })}{\left(\begin{array}{l}
\text { value obtained by substittuting the conditions of experiments } \\
\text { and surveys into the prediction formula of the Verification Method }
\end{array}\right)}
$$

Here, the suffix var corresponds to the name of the variable to be estimated; $t_{s t a r t}, \alpha_{f}$, or $t_{s}$.

\subsubsection{Walking Velocity (v) [m/min]}

Many studies can be found on the subject of walking speed. Some of the characteristics of a building used for offices are as follows: 1) the building is being used daily, and 2) most of the occupants are adults who are able to escape by themselves. Also, since the Occupant Density is relatively low, it is not very likely that the occupants will have to walk as a crowd of high density. In this study, we have used the results measured in the previous surveys on buildings used by specific people that provided walker density of 1.2 [persons $/ \mathrm{m}^{2}$ ] or less (except the range where deceleration occur due to crowded walking situation)[13,14]. The result is shown in Figure 5. The mean value is $73.1[\mathrm{~m} / \mathrm{min}$, which is slightly smaller than the prescribed values of the Verification Method. The standard deviation is $9.5[\mathrm{~m} / \mathrm{min}]$, which is not remarkably large. 


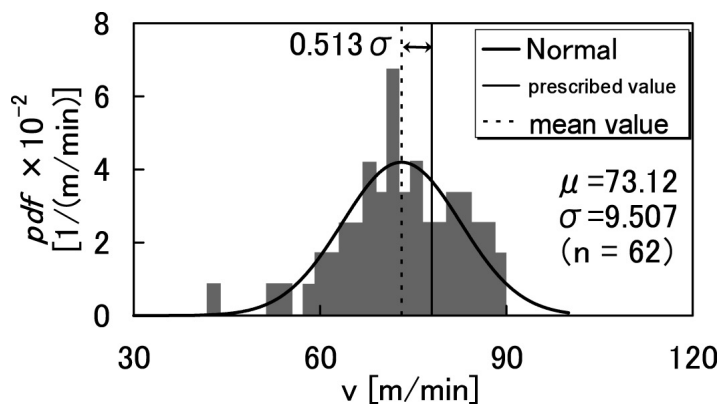

Figure 5 Result of the Study on the Walking Velocity $v$ [m/min] and Probability Density Function (for walker density of 1.2 [persons/m2] or less)

\subsubsection{Flow Rate $(N)$ [Persons/(m.min)]}

Results for train doors and theater exits are available for the measured values of Flow Rate through a door[15,16]. It was recognized from the comparison of these two results that the former showed a larger value. This is because in the former case the walkers are psychologically urged to pass through the door and be relieved from the situation, a situation is similar to that of an evacuation from the room or the floor on fire. Therefore, in this study, the measured value of Flow Rate in the case of a train door is adopted, and a $p d f$ was derived. As shown in Figure 6, the result is given with the following equation:

$$
N=\operatorname{Normal}(111,18.3)[\text { persons } /(\mathrm{m} \cdot \mathrm{min})]
$$

As seen from the figure, the prescribed value of the Verification Method is slightly smaller than the mean value.

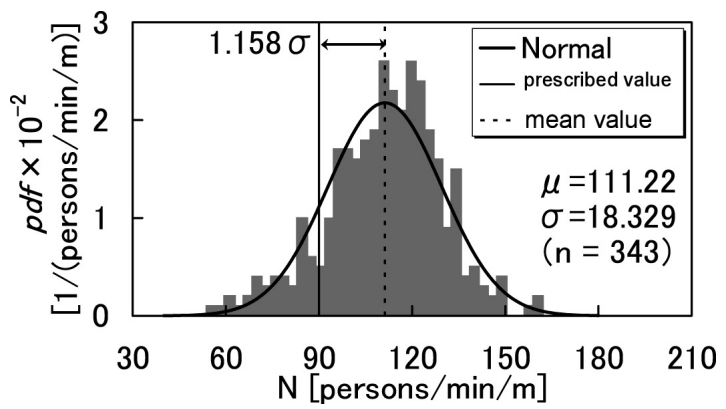

Figure 6 Result of the Study on the Flow Rate N [Persons/m·min] and Probability Density Function

\subsubsection{Compensating Rate of the Fire Room at the Egress Start Time (ftstart) [-]}

The Egress Start Time (the time interval before starting evacuation) in the Verification Method is given using the square root of the floor area of the fire room:

$$
t_{\text {start }, D}=\sqrt{A_{\text {room }}} / 30 \quad[\mathrm{~min}]
$$


However, it is estimated that the Egress Start Time depends not only on the floor area but it also concerns the recognition of smoke or flames by the occupants at the initial stages of the fire. At present, the accumulation of data concerning the researches on the Egress Start Time in relation to the situation of fire is not sufficient to estimate a $p d f$. Therefore, concerning room evacuation, a model was created that is considered to be close to reality, and calculation was performed under the expected dimensional conditions for office room to get the convincingly alternative measured data.

Since there is considerable visibility and the occupants are awake in an office, it is considered that evacuation will be begun when the occupants have realized there is smoke or flames from a fire. Therefore, the recognition of fire was defined as the time when either 1) the thickness of the smoke layer had reached 1/10 of the ceiling height, or 2 ) the heat release rate (hereafter referred as HRR) had reached $600 \mathrm{~kW}$ corresponding to the measurement of the flames were clearly visible.

There is always an uncertainty in the time from the recognition of fire to the actual starting evacuation depending on the individuals. Although the distribution is uncertain, in this study, we have adopted a lognormal distribution LogNormal $(1,2)$ [Note3]. Note that all situations considered in the passage above are emergency situations, and may be considered that recognition of fire will lead to an immediate start of evacuation. Here, one minute corresponding to the mean value will be subtracted.

Under these assumptions, the Egress Start Time will be calculated with (10). In the first term on the right hand side of Equation (10), the top equation in the open bracket is an equation obtained by substituting 0.9 times as the room height $H_{\text {room }}[\mathrm{m}]$ with the height of the inferior surface of the smoke layer in the simplified equation ${ }^{17}$ ) (an equation that has proven to provide a fairly good estimation of the Smoke Filling Time), and rounding up the various constants. Whereas the bottom equation in the bracket is obtained by adopting a model equation of HRR in the fire growth (obtained by equating the HRR $[\mathrm{kW}]$ to the time $[\mathrm{s}]$ squared multiplied by Fire Growth Rate $\left.\left(\alpha_{f}+\alpha_{m}\right)\left[\mathrm{kW} / \mathrm{s}^{2}\right]\right)$, and solving the equation with respect to time, and substituting $600 \mathrm{~kW}$ as the HRR.

$$
\begin{aligned}
& t_{\text {start }, \text { cal }}=\min \left\{\begin{array}{l}
\left(\frac{\left(0.9 H_{\text {room }}\right)^{-2 / 3}-H_{\text {room }^{-2 / 3}}}{0.028\left(\alpha_{f}+\alpha_{m}\right)^{1 / 3} A_{\text {room }}{ }^{-1}}\right)^{3 / 5} \div 60 \\
\sqrt{\frac{600}{\alpha_{f}+\alpha_{m}}} \div 60
\end{array} \quad[\mathrm{~min}]\right.
\end{aligned}
$$

A typical office is considered for the calculation. The parameters are selected as follows: the floor area $A_{\text {room }}$ is randomly sampled from the range between $50-1500 \mathrm{~m}^{2}$; the height of the ceiling is selected as $2.66 \mathrm{~m}$ (a value corresponding to the average obtained by the survey in this study, as shown in Figure 27); the Fire Growth Rate of the interior finishing material $\alpha_{m}$ is selected as $0.014 \mathrm{~kW} / \mathrm{s}^{2}$ (a value for Quasi-noncombustible materials); and 
the Fire Growth Rate of the Fuel Load $\alpha_{f}$ is obtained by substituting the value of Fuel Load Density $q_{l}$ randomly sampled according to Equation (6) into Equation (11).

Figure 7 shows the result of calculations for 1000 samples compared with the values obtained using Equation (9). Although the uncertainty is large, Equation (9) multiplied by 2 will provide the mean value of the Egress Start Time obtained by calculation using the model constructed above. Figure 8 shows the same result expressed as a histogram. Although the shape of the distribution is rather different (deviation of most frequent value can be seen), lognormal distribution was adopted since the probability of the cases where the Egress Start Time take extremely large values cannot be neglected. These $p d f \mathrm{~s}$ will be used in the simulation by Monte-Carlo method to analyze the Target Safety Index (obtained as the average value divided by the standard deviation - independent of the shape of the distribution) and the Acceptable Probability of Failure (expressing the possibility of non-safety - a value with a dependency on the shape of the outer skirts of the curve). These will be explained later in detail. Concerning the Compensating Rate for the Egress Start Time, a larger value will produce non-safety, and Figure 9 shows the accumulation of the values in Figure 8. In Figure 9, the values of the two results fits well in the region where the values are large, hence, it can be said that lognormal distribution is adequate for use in the later analysis.

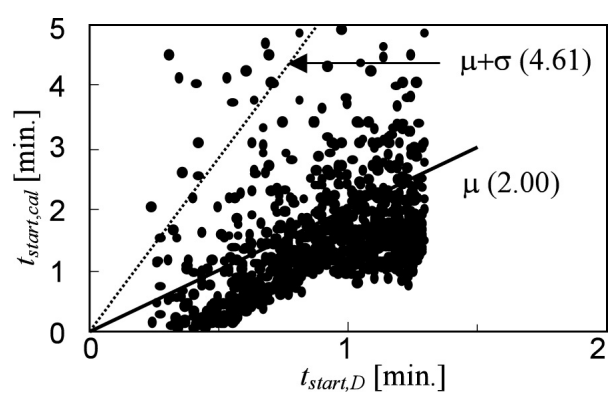

Figure 7 Compensating Rate for the Egress Start Time of the Fire Room $\left(A_{\text {room }}=50-1500 \mathrm{~m}^{2}, H_{\text {room }}=2.66 \mathrm{~m}, q_{l}=\operatorname{LogNormal}(235,65.4) \mathrm{MJ} / \mathrm{m}^{2}, \alpha_{m}=0.014 \mathrm{~kW} / \mathrm{s}^{2}, 1000\right.$ samples $)$

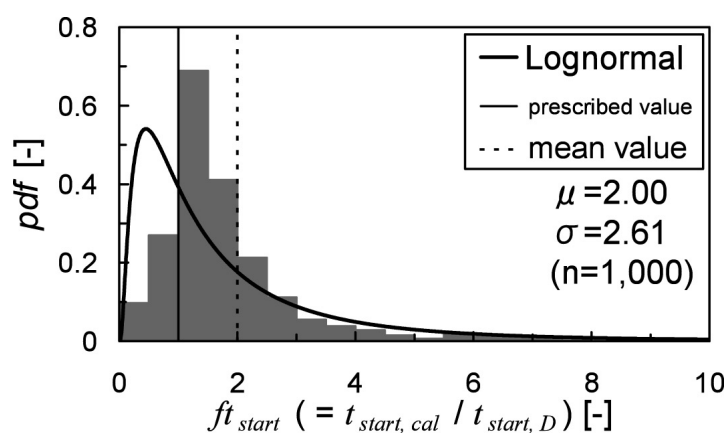

Figure 8: Result of Estimation of the Compensating Rate ftstart for the Egress Start Time of the Fire Room and Probability Density Function 


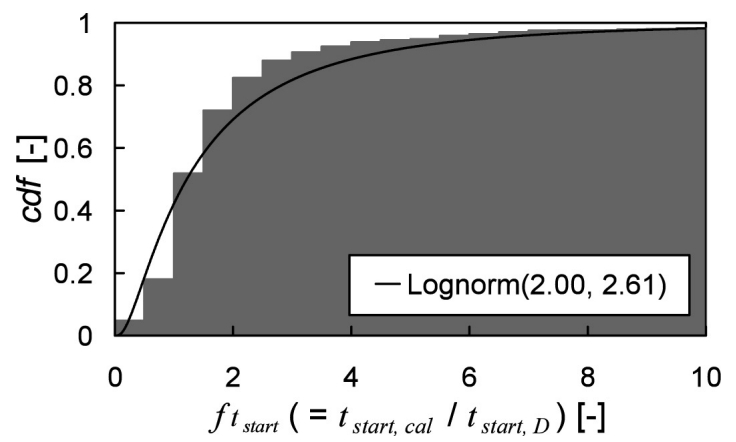

Figure 9 Cumulated Relative Probability of the Compensating Rate $f_{\text {tstart }}$ for the Egress Start Time of the Fire Room and the Cumulative Distribution Function

\subsubsection{Fire Growth Rate of the Fuel Load $\left(\alpha_{f}\right)\left[\mathrm{kW}^{2} \mathrm{~s}^{2}\right]$}

In the Verification Method, the Fire Growth Rate of the Fuel Load will be calculated from Equation (11) as a function of its Fuel Load Density. There are 4 examples of full large scale fire tests where the Fuel Load Density and the Fire Growth Rate of the Fuel Load have both been measured [18-21].

There are 11 examples [22-26] without a clear description on HRR, but containing data on the time to flash over (hereafter referred to as FO). As for those examples where the time to FO is known, the HRR was reverse-calculated from the time of the occurrence of FO, to estimate the Fire Growth Rate. According to McCaffrey et al., the relation between the fire temperature and HRR is given with the following equation [27]:

$$
Q=\left(\Delta T / 0.0236 T_{\infty}\right)^{3 / 2}\left(A_{T} \sqrt{k \rho c} A \sqrt{H}\right)^{1 / 2} t^{1 / 6}
$$

First, the condition for the occurrence of a FO (the time when the temperature within the combustion compartment reaches $600^{\circ} \mathrm{C}$ or the time and the temperature when a sudden rise in the temperature had occurred) is retrieved from experimental data. Next, the HRR at the time of the FO is derived by substituting this condition together with the experimental conditions (wall area $A_{T}\left[\mathrm{~m}^{2}\right]$, thermal inertia $\sqrt{k \rho c}\left[\mathrm{~kW} / \mathrm{s}^{1 / 2} \cdot \mathrm{m}^{2} \cdot \mathrm{K}\right]$, opening factor $A \sqrt{H}\left[\mathrm{~m}^{5 / 2}\right]$ into Equation (12). Finally, the Fire Growth Rate $\alpha_{f, e x p}$ is obtained by dividing this value by the time of FO squared.

On the other hand, the Fuel Load Density $q l$ in each experiment is substituted into the prediction formula Equation (11) to obtain the Fire Growth Rate $\alpha_{f, D}$, and the ratio of the two results is calculated as $f_{\text {af }}\left(=\alpha_{f(e x p} / a_{f, D}\right)$. Results from a total of 15 experiments were collected to obtain Figure 10. 


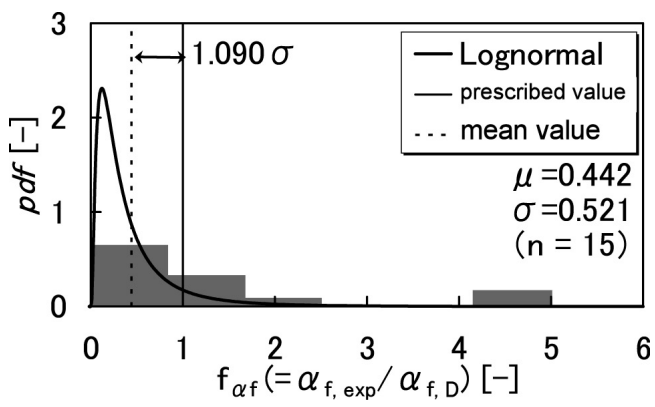

Figure 10 The Uncertainty of the Compensating Rate $f_{\text {af }}[-]$ of the Fire Growth Rate (Fire Growth Rate of the Fuel Load) and Probability Density Function

\subsubsection{Fire Growth Rate of Interior Finishing Material $\left(\alpha_{m}\right)\left[\mathrm{kW} / \mathrm{s}^{2}\right]$}

In the Verification Method, the value of the HRR of the interior finishing material is prescribed according to the type of the material (noncombustible, quasi-noncombustible, fire-retardant, wood and the equivalent material to this. However, in reality, materials belonging to the same category will present differences in the spread of fire. Regarding this situation, a simple model is constructed describing the spread of combustion along the surface of the interior finishing material to create a $p d f$ from the result of estimation of the Fire Growth Rate of the various types of material.

It would be quite natural to assume that a quasi-noncombustible material is used in a typical office space, in which case, a material on which the fire will show a vigorous vertical propagation directly after initiation can be ruled out. Therefore, it is considered that the portions in contact with the flame from the fuel load will sequentially start burning. Therefore, the HRR $Q_{m}(t)[\mathrm{kW}]$ of the interior finishing material at a given time $t$ will be given by taking the product of the increasing rate of the area of flame in contact $\partial A_{w}(t) / \partial t$ against the HRR per unit surface area after the material has caught the flame $q_{w}(t)$, and taking a integration over time:

$$
Q_{m}(t)=\int_{0}^{t} \frac{\partial A_{w}(t-\tau)}{\partial \tau} q_{w}(\tau) d \tau
$$

The area in contact with the flame is calculated under the assumption that the source of fire is in a corner of the room (see Figure 11), and the heat release rate of the fire source $Q_{f}(t)$ and the radius of the fire source $R_{f}[\mathrm{~m}]$ are provided by the following equations [Note 4].

$$
\begin{aligned}
& Q_{f}=(1 / 4) \alpha_{f} t^{2} \quad[\mathrm{~kW}] \\
& R_{f}=\sqrt{\frac{4}{\pi} A_{f}}=\sqrt{\frac{4}{\pi} \frac{Q_{f}}{1600}}=\sqrt{\frac{\alpha_{f}}{400 \pi}} t \quad[\mathrm{~m}]
\end{aligned}
$$

Here, $q_{l}=560 \mathrm{MJ} / \mathrm{m}^{2}$ is substituted into Equation (11) to yield the value $\alpha_{f}=0.0989$

The value $q_{w}(t)$ of heat release rate per unit surface area of the material is obtained 
by referencing the result of the Room-Corner Fire Test. As shown in Figure 12, the HRR of a quasi-noncombustible material shows a peak immediately after increasing the HRR of the burner from $100 \mathrm{~kW}$ to $300 \mathrm{~kW}$. The value $q_{w}(t)$ is calculated for each material tested by dividing the HRR at the position showing a peak by the difference in the area in contact with the flame between $100 \mathrm{~kW}$ and $300 \mathrm{~kW}$.

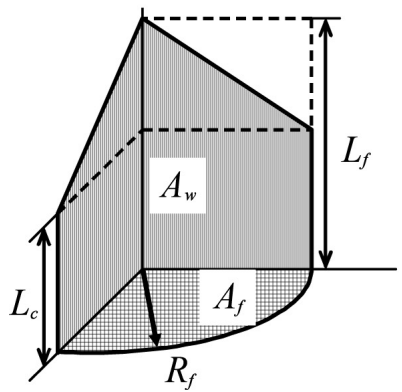

$A_{f}$ : floor area of fire source $\left[\mathrm{m}^{2}\right]$

$A_{w}:$ surface area in contact with the flame $\left[\mathrm{m}^{2}\right]$

$L_{c}$ : flame height $[\mathrm{m}]$

$L_{f}$ : height of the tip of the flame [m]

$R_{f}$ : fire source radius $[\mathrm{m}]$

Surface area of Interior Finishing Material

in contact with the flame $\left[\mathrm{m}^{2}\right]$

$A_{w}=2 R_{f} L_{c}+R_{f}\left(L_{f}-L_{c}\right)$

$=R_{f}\left(L_{c}+L_{f}\right)$

Figure 11 Combustion Area Model for Interior Finishing Material

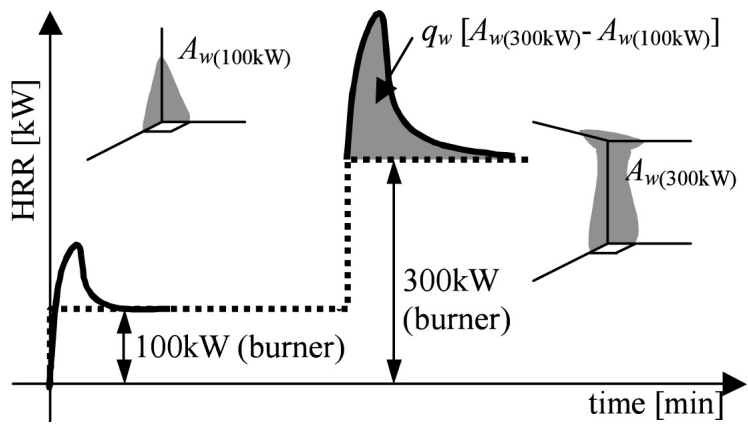

Figure 12 Combustion Pattern of a Quasi-noncombustible Material in Room-Corner Fire Test

The analysis was performed against the 11 samples that fall under the category of quasi-noncombustible materials from the Ministry of Construction's project on comprehensive engineering development [28]. As shown in Figure 13, the result is given as follows:

$$
\alpha_{m}=\operatorname{LogNormal}(0.034,0.044)
$$

The mean value is 0.034 , which is slightly large compared with the value prescribed in the Verification Method. Some of the values are extremely large, and the level of uncertainty is high. 


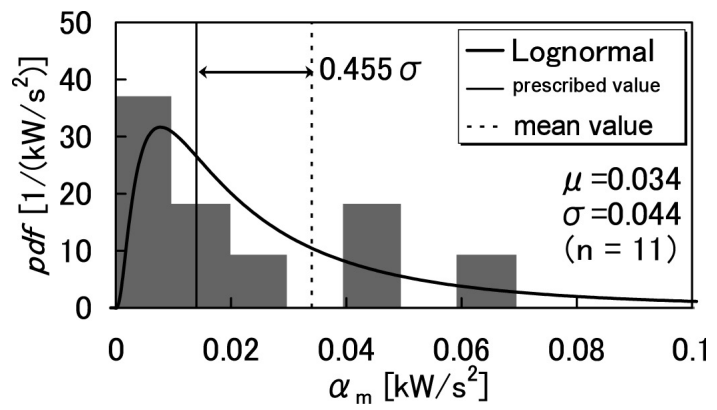

Figure 13 Uncertainty of the Fire Growth Rate $\alpha_{m}$ of an Interior Finishing Material (Quasi-noncombustible Material) $\left[\mathrm{kW} / \mathrm{s}^{2}\right]$ and Probability Density Function

\subsubsection{Compensating Rate of the Smoke Filling Time $\left(f_{t 5}\right)[-]$}

The Smoke Filling Time in the Verification Method is calculated with the following equation, dividing the volume of smoke that can be contained in the upper part of the room by the volume of smoke accumulated (the difference between the smoke generating and smoke ventilation) per unit time:

$$
t_{s}=\frac{\left(H_{\text {room }}-H_{\text {lim }}\right) \cdot A_{\text {room }}}{\max \left(V_{s}-V_{e}, 0.01\right)}
$$

Although the expression has been simplified in the equation above, it basically calculates the smoke filling time by predicting the fire plume at the initial stages of fire. Therefore, representing the measured results on smoke filling time obtained from existing full large scale tests [29-36] with $t_{s, \exp }$, the ratio $f_{t s}\left(=t_{s, \text { exp }} / t_{s, D}\right)$ was calculated between $t_{s, \exp }$ and $t_{s, D}$, which is a value obtained by substituting the conditions used in the tests into Equation (17) [Note 5]. The results are presented in three groups according to the type of Smoke Control System adopted by the room under consideration: Smoke Filling System, Natural Ventilation System, and Mechanical Ventilation System.

For Smoke Filling System, 28 experimental results were obtained. Although it is possible to simply collect the data and create a $p d f$, there is a clear interrelation between these values and the floor area $A_{\text {room }}$ as shown in Figure 14. The Compensating Rate will be around 2 in a room with a large floor area, whereas in a smaller room, the Compensating Rate tends to become extremely large. Therefore, approximating the dependence of the value to the floor area with power series, $p d f$ is calculated using the residuals as the random errors. This is shown in Figure 15. Finally, the Compensating Rate of the Smoke Filling Time is determined as follows:

$$
f_{t s}=5.64 A_{\text {room }}^{-0.144}+\operatorname{Normal}(0,0.586)
$$

It is also possible to estimate the dependence of the floor area etc. on the spatial dimensions of rooms adopting Natural Ventilation Systems and Mechanical Ventilation Systems, however, the amount of data available for these cases were not sufficient to determine the relation (only 5 cases for Natural Ventilation System and 8 cases for 
Mechanical Ventilation System were available). Hence, for Natural Ventilation System and Mechanical Ventilation System, the results were simply collected to calculate the $p d f \mathrm{~s}$. The results are shown in Figures 16 and 17. In both cases, the mean value is slightly over 2, and the prediction formula in the Verification Method is mainly used for the estimation of the safe side.

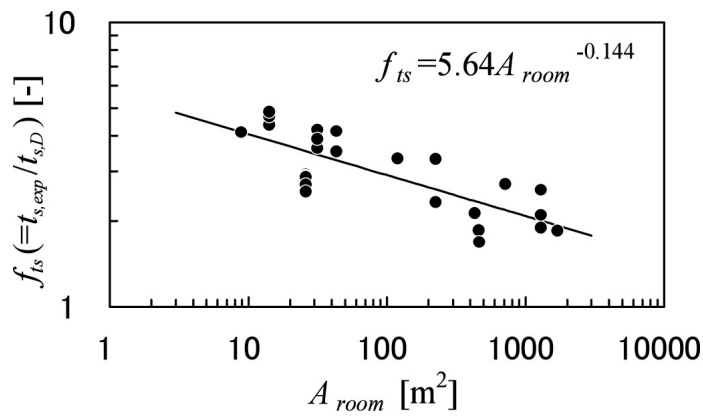

Figure 14 Inter-relation between the Compensating Rate $f_{t s}$ of the Smoke Filling Time and the Floor Area $A_{\text {room }}$

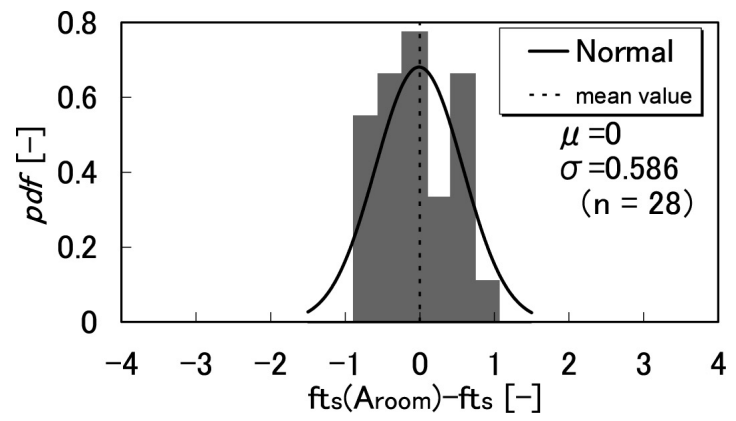

Figure 15 The Residual of the Compensating Rate $\left(f_{t s}-5.64 A_{\text {room }}^{-0.144}\right)$ of the Smoke Filling Time (for Smoke Filling System) and Probability Density Function

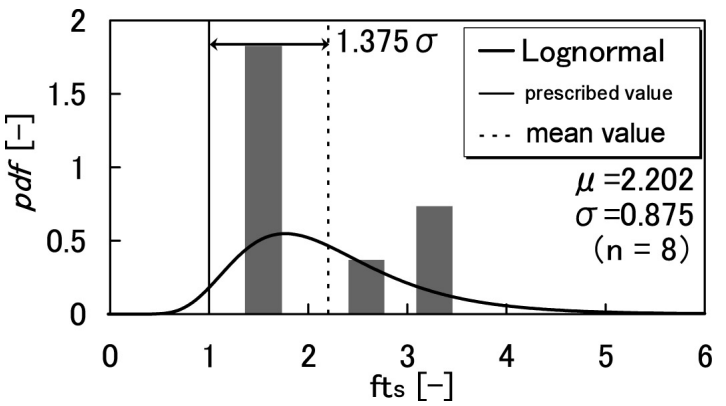

Figure 16 The Uncertainty of the Compensating Rate $f_{t s}[-]$ of the Smoke Filling Time of the Fire Room (Natural Ventilation System) and Probability Density Function 


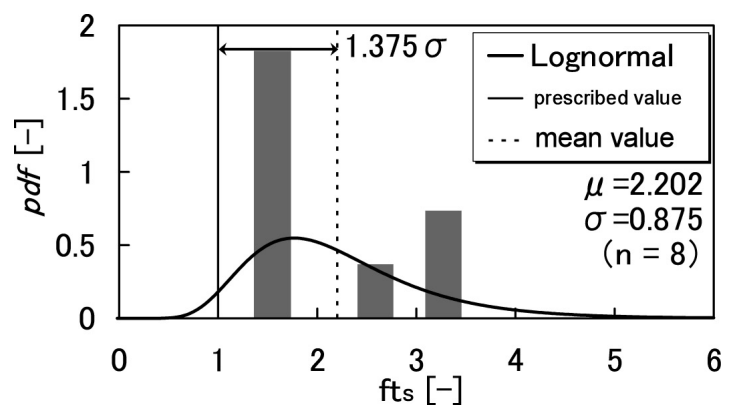

Figure 17 The Uncertainty of the Compensating Rate $f_{\text {ts }}[-]$ of the Smoke Filling Time of the Fire Room (Mechanical Ventilation System) and Probability Density Function

\subsection{Consideration}

\subsubsection{Variation Coefficient for Each Variable}

The Probability Density Function ( $p d f)$ obtained in Sections 3.1 and 3.2 for Type A and Type B variables are presented in Table 1. This table also presents the variation coefficients $\eta_{x}$ calculated using the following equation in order to compare the degree of valiability of the stochastic variables.

$$
\eta_{x}=\left(\sigma_{x} / \mu_{x}\right) \times 100 \quad[\%]
$$

The Variation Coefficient of Type A variables are 28\% for Fuel Load Density and 57\% for Occupant Density. In both variables the variations are not small.

For Type B variables, the uncertainty of the Walking Velocity and Flow Rate are small, however, the Variation Coefficients for the other four variables (i.e. Compensating Rate for the Egress Start Time of the fire room, Fire Growth Rate of the interior finishing material, Fire Growth Rate of the fuel load, and Smoke Filling Time) exceed $100 \%$, which implies that there is an extremely large uncertainty. The improvement of the precision for the estimation of these four variables is awaited.

\subsubsection{Partial Safety Factor and Probability of Exceedance corresponding to the prescribed value in the Verification Method}

Partial Safety Factor $\gamma_{\mathrm{x}}$ corresponding to the Prescribed Value $\mathrm{x}_{D}$ of the Verification Method is calculated using the following equation [Note 6]:

$$
\gamma_{x}= \pm\left(x_{D}-\mu_{x}\right) / \sigma_{x}
$$

and Probability of Exceedance $P_{e x}$ is calculated according to the $p d f$ s obtained in Sections 3.1 and 3.2. Here, Partial Safety Factor defined as shown in Figure 18 represents how far apart the prescribed value of each variable is from the mean value $\mu_{x}$, when measured in terms of the standard deviation $\sigma_{x}$. The results are shown in Table 2. 
Table 1 List of Probability Density Function of Type A and Type B Variables and Variation Coefficient

\begin{tabular}{|c|c|c|c|c|c|}
\hline Type & \multicolumn{2}{|c|}{ Stochastic Variables } & $\begin{array}{l}\text { Number of } \\
\text { Samples }\end{array}$ & $\begin{array}{l}\text { Probability Density Function } \\
(p d f)\end{array}$ & $\begin{array}{c}\text { Variation } \\
\text { Coefficient [\%] }\end{array}$ \\
\hline \multirow{2}{*}{ A } & \multicolumn{2}{|c|}{ Occupant Density: $p$ [persons $/ \mathrm{m}^{2}$ ] } & 393 & LogNormal $(0.122,0.070)$ & 57 \\
\hline & \multicolumn{2}{|c|}{ Fuel Load Density: $q_{l}\left[\mathrm{MJ} / \mathrm{m}^{2}\right]$} & 5 & LogNormal $(235,65.4)$ & 28 \\
\hline \multirow{8}{*}{ B } & \multicolumn{2}{|c|}{ Walking Velocity: $v[\mathrm{~m} / \mathrm{min}]$} & 62 & Normal $(73.1,9.51)$ & 13 \\
\hline & \multicolumn{2}{|c|}{ Flow Rate: $N$ [persons $/ \mathrm{m} / \mathrm{min}$ ] } & 343 & Normal $(111,18.4)$ & 17 \\
\hline & \multicolumn{2}{|c|}{$\begin{array}{l}\text { Compensating Rate for the Egress } \\
\text { Start Time of the Fire Room: } f_{\text {start }}[-]\end{array}$} & $(1000)^{*}$ & LogNormal $(2.00,2.61)$ & 131 \\
\hline & \multicolumn{2}{|c|}{$\begin{array}{l}\text { Compensating Rate for the Fire } \\
\text { Growth Rate of the Fuel Load: } f_{\text {of }} \\
{\left[\mathrm{kW} / \mathrm{s}^{2}\right]}\end{array}$} & 15 & LogNormal $(0.442,0.521)$ & 118 \\
\hline & \multicolumn{2}{|c|}{$\begin{array}{l}\text { Fire Growth Rate of } \\
\text { Interior Finishing Materials } \\
\text { (Quasi-noncombustible): } \alpha_{m}\left[\mathrm{~kW} / \mathrm{s}^{2}\right]\end{array}$} & 11 & LogNormal $(0.034,0.044)$ & 129 \\
\hline & \multirow{3}{*}{$\begin{array}{l}\text { Compensating } \\
\text { Rate for Smoke } \\
\text { Filling Time: } f_{t s}[-]\end{array}$} & $\begin{array}{l}\text { Smoke Filling } \\
\text { System }\end{array}$ & 28 & $\begin{array}{l}5.64 \mathrm{~A}_{\text {room }}{ }^{-0.144} \\
+ \text { Normal } \\
(0,0.586)\end{array}$ & 223 \\
\hline & & $\begin{array}{l}\text { Natural } \\
\text { Ventilation } \\
\text { System }\end{array}$ & 5 & LogNormal $(2.350,0.470)$ & 235 \\
\hline & & $\begin{array}{l}\text { Mechanical } \\
\text { Ventilation } \\
\text { System }\end{array}$ & 8 & LogNormal $(2.202,0.875)$ & 220 \\
\hline
\end{tabular}

* Number of Samples used for the Model Calculation

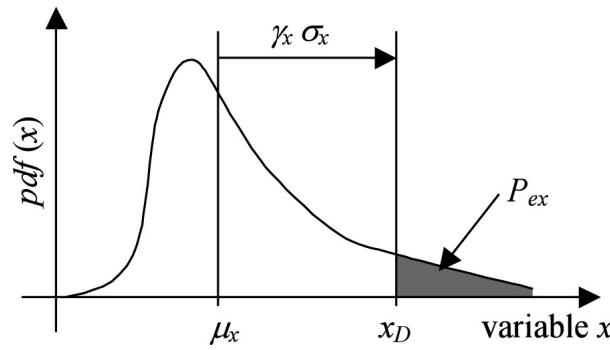

Figure 18 Partial Safety Factor Corresponding to the Prescribed Value in the Verification Method and the Probability of Exceedance 
Table 2 The List of Prescribed Values, Partial Safety Factor, and the Probability of Exceedance in the Verification Method for Type A and Type B variables

\begin{tabular}{|c|c|c|c|c|c|c|}
\hline \multirow[b]{2}{*}{ Type } & \multirow{2}{*}{\multicolumn{2}{|c|}{$\begin{array}{l}\text { Stochastic } \\
\text { Variables }\end{array}$}} & \multirow{2}{*}{$\begin{array}{l}\text { Probability Density } \\
\text { Function }\end{array}$} & \multicolumn{3}{|c|}{$\begin{array}{l}\text { The Prescribed Value in the } \\
\text { Verification Method }\end{array}$} \\
\hline & & & & $\begin{array}{l}\text { Prescribed } \\
\text { Value }\end{array}$ & $\begin{array}{l}\text { Partial } \\
\text { Safety } \\
\text { Factor }\end{array}$ & $\begin{array}{l}\text { Probability of } \\
\text { Exceedance[\%] }\end{array}$ \\
\hline \multirow{2}{*}{ A } & \multicolumn{2}{|c|}{$p\left[\right.$ persons $\left./ \mathrm{m}^{2}\right]$} & LogNormal $(0.122,0.070)$ & 0.125 & 0.043 & 37.7 \\
\hline & \multicolumn{2}{|c|}{$q_{l}\left[\mathrm{MJ} / \mathrm{m}^{2}\right]$} & LogNormal $(235,65.4)$ & 560 & 4.97 & 0.1 or less \\
\hline \multirow{8}{*}{ B } & \multicolumn{2}{|c|}{$v[\mathrm{~m} / \mathrm{min}]$} & Normal $(73.1,9.51)$ & 72 & 0.116 & 48.2 \\
\hline & \multicolumn{2}{|c|}{$N[$ persons/m.min] } & Normal $(111,18.4)$ & 90 & 1.14 & 12.7 \\
\hline & \multicolumn{2}{|c|}{$f_{t_{\text {start }}}[-]$} & LogNormal $(2.00,2.61)$ & 1 & -0.383 & 57.8 \\
\hline & \multicolumn{2}{|r|}{$f_{\alpha f}[-]$} & LogNormal $(0.442,0.521)$ & 1 & 1.07 & 9.0 \\
\hline & \multicolumn{2}{|c|}{$\alpha_{m}\left[\mathrm{~kW} / \mathrm{s}^{2}\right]$} & LogNormal $(0.034,0.044)$ & 0.014 & -0.455 & 65.5 \\
\hline & \multirow{3}{*}{$f_{t_{S}}[-]$} & $\begin{array}{l}\text { Smoke } \\
\text { Filling } \\
\text { System }\end{array}$ & $\begin{array}{l}5.64 \text { room }^{-0.144}+ \\
\quad \text { Normal }(0,0.586)\end{array}$ & $1^{*}$ & $2.23 *$ & $12.7^{*}$ \\
\hline & & $\begin{array}{c}\text { Natural } \\
\text { Ventilation } \\
\text { System }\end{array}$ & LogNormal $(2.350,0.470)$ & 1 & 2.87 & 0.1 or less \\
\hline & & $\begin{array}{c}\text { Mechanical } \\
\text { Ventilation } \\
\text { System }\end{array}$ & LogNormal $(2.202,0.875)$ & 1 & 1.37 & 9.7 \\
\hline
\end{tabular}

* Value corresponding to $A_{\text {room }}=500 \mathrm{~m}^{2}$

Probability of Exceedance show larger values with the following variables: Occupant Density (37.7\%), Walking Velocity (48.2\%), Egress Start Time (57.9\%), Fire Growth Rate of interior finishing material (Quasi-noncombustible) (65.5\%). On the other hand, Probability of Exceedance is small with the following variables: Fuel Load Density (0.1 or less), Compensating Rate for Smoke Filling Time (12.7\%, 0.1\% or less, 9.7\%).

Although it will also depend on the degree of influence (sensitivity) of each of the variables, the configuration of the variables concerning the prediction of time to evacuation such as Egress Start Time and Occupant Density are close to the mean value, whereas there are large allowances in the variables related to the prediction of the physical phenomenon of smoke such as Fuel Load Density and Smoke Control (Compensating Rate for Smoke Filling Time).

Figure 19 shows the relation between Partial Safety Factor and Variation Coefficient corresponding to the prescribed value of each variable. Hardly any dependency can be seen between the Partial Safety Factor and the large or small of the Variation Coefficient. Partial Safety Factor shows a random distribution in the range between 
-0.45 to 4.97. Partial Safety Factor of a typical engineering system typically takes a value between 0 and 2 . The values presented here are out of the normal range, hence, there leaves much room for adjustments on the configuration for a better balance. Concerning Partial Safety Factor, i.e. the configuration of the prescribed input value, it is possible to consider an optimal balance taking into account the influence (sensitivity) that the variation of the individual Stochastic Variable poses on the variation of the Egress Time Margin. A proposal is given in a later section of this paper.

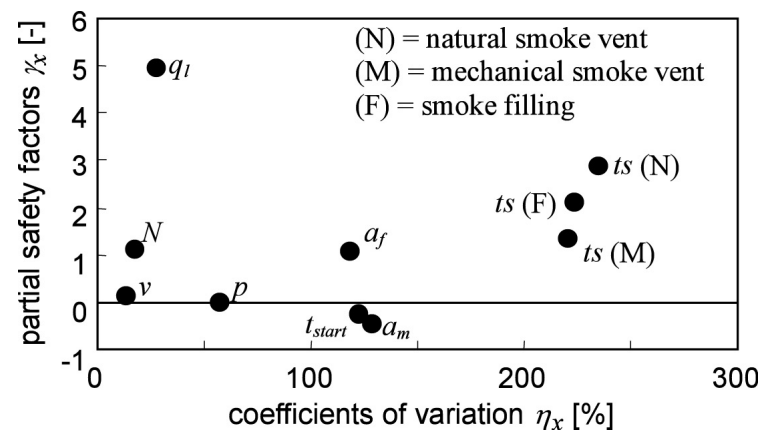

Figure 19 Relation between Variation Coefficient and Partial Safety Factor for Each Stochastic Variable

\section{EVALUATION OF THE SAFETY LEVEL AND THE MOST PROBABLE FAILURE POINT OFTHE CALCULATION SYSTEM}

\subsection{Evaluation Method}

\subsubsection{Expression of the Safety Level}

As it was evaluated in Section 3, the Verification Method possesses two Type A variables: Occupant Density $p$ [persons $\left./ \mathrm{m}^{2}\right]$, and Fuel Load Density $q_{l}\left[\mathrm{MJ} / \mathrm{m}^{2}\right]$. Based on the Probability Density Function ( $p d f)$ of these two variables, counters $p d f\left(p, q_{l}\right)$ can be drawn for the Probability of Occurrence as shown in Figure 20. The curve drawn in the figure with the thick line (hereafter referred to as the "Limit State Line") shows the combination of $p$ and $q_{l}$ where $t_{\text {margin }}=0$ is provided by applying the Verification Methods to a particular building plan. Probability of Occurrence in the upper right region above the Limit State Line corresponds to the region of Probability of Failure $p_{f}$, therefore is an index for the Safety Level of building plans.

The point (the combination of $p$ and $q_{p}$ ) on the Limit State Line where the Probability of Occurrence becomes highest is called Most Probable Failure Point (MPFP). Safety Index $B$ is defined as the distance between the mean value of $\left(p, q_{l}\right)$ and the MPFP normalized (divided) by the standard deviation [37]. 


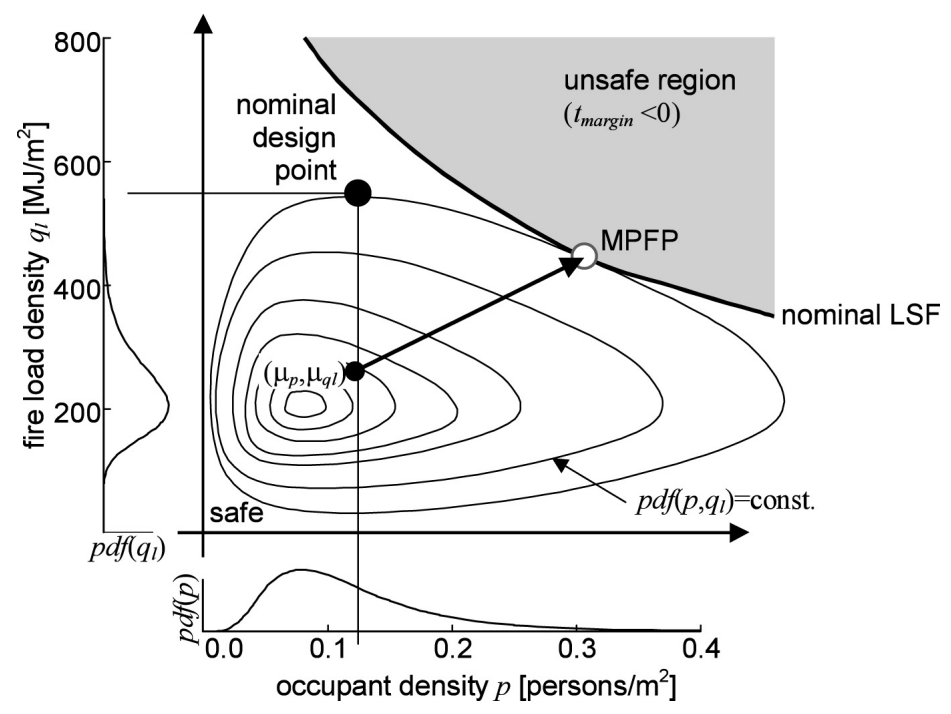

Figure 20 Safety Level of the Verification Method from the Methodology of Reliability Engineering

\subsubsection{Acceptable Probability of Failure $p_{f}$ and Target Safety Index $\beta$}

It is required that in order for a building plan to fulfill the requirements of the Verification Method, the value of Egress Time Margin at the prescribed Design Point $\left(p_{D}, q_{I D}\right)=(0.125,560)$ must be 0 or larger.

$$
t_{\text {margin }}\left(p_{D}, q_{l, D}\right) \geq 0
$$

This condition is equivalent to the condition that the Limit State Line in Figure 20 passes overhead and to the right, looking from the prescribed Design Point. This implies that for a building plan to conformance to the Verification Method, a certain Level of Safety is ensured within itself.

The Limit State Line shown in Figure 20 corresponds to a specific building plan; therefore it is acceptable to trim the margin for the design so that the Egress Time Margin at the Design Point $\left(p_{D}, q_{I D}\right)$ zeros. Therefore, the Level of Safety required by the Verification Method is made clear by investigating the Safety Level of the building plan that provides zero for Egress Time Margin at the prescribed Design Point.

In reality, it is rare to encounter a building plan that provides an Egress Time Margin of zero at the Design Point, therefore, samples obtained have not been enough to provide any solid conclusion about this scheme. Consequently, by subtracting the Egress Time Margin $t_{\text {margin }}\left(p_{D}, q_{l, D}\right)$ at the prescribed Design Point in the Verification Method from the Egress Time Margin $t_{\text {margin }}\left(p, q_{l}\right)$ at a certain Design Point for a specific building plan, it is possible to obtain, as an approximate solution, the Limit State Function (a function expressing the Limit State Line) for a building plan that provides zero for the Egress Time Margin at the prescribed Design Point in the Verification Method (see Figure 21).

$$
G\left(p, q_{l}\right)=t_{\text {margin }}\left(p, q_{l}\right)-t_{\text {margin }}\left(p_{D}, q_{l_{D}}\right) \geq 0
$$


In addition, Type B variables analyzed in Section 3.3 are added in order to take the uncertainty of the prediction formula into account.

$$
\begin{aligned}
& G(\mathbf{x})=t_{\text {margin }}(\mathbf{x})-t_{\text {margin }}\left(\mathbf{x}_{D}\right) \\
& \mathbf{x}=\left\{p, q_{l} ;, v, t_{\text {start }}, \alpha_{f}, \alpha_{m}, t_{s}\right\} \\
& \mathbf{x}_{D}=\left\{p_{D}, q_{l_{D}} ; v_{D}, N_{D}, t_{\text {start }}, \alpha_{f_{D}}, \alpha_{m_{D}}, t_{S_{D}}\right\}
\end{aligned}
$$

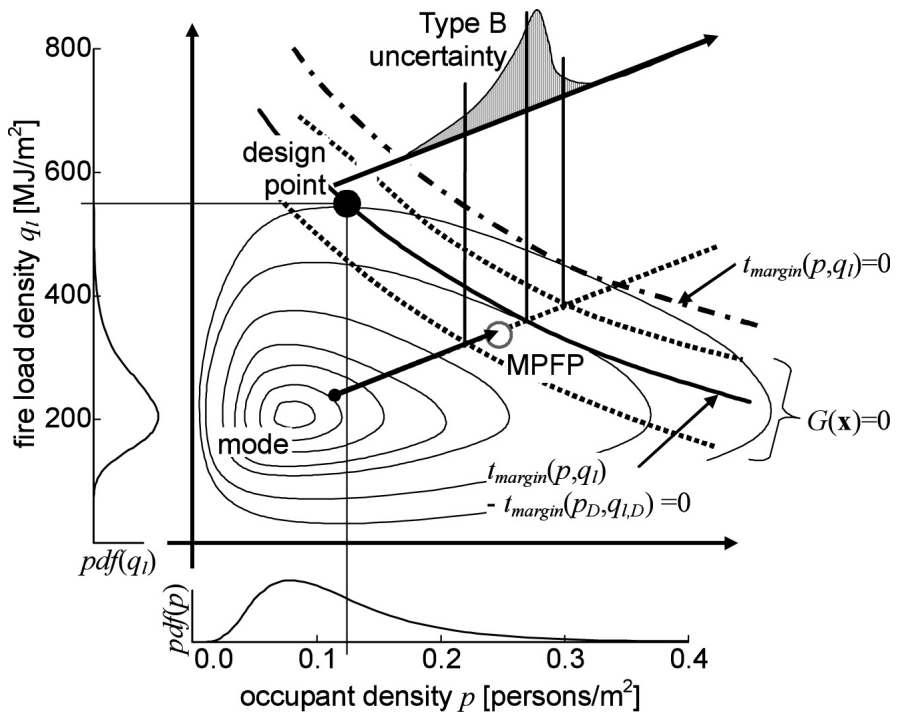

Figure 21 Safety Level Requested in the Verification Method

Studying the characteristics of the function $G(\mathbf{x})$ defined above, the Safety Level required in the Verification Method can be quantified [Note 7]. The Egress Time Margin is evaluated by assigning the design values depicted from a specific building plan (e.g. floor area, ceiling height, width of the exit door, etc.) and the values randomly sampled according to the Probability Density Function of Type A and Type B variables in the Verification Method. Fixing the design values, and sampling the Stochastic Variables (Type A and Type B variables) by Monte-Carlo simulation, the distribution of probability density of the Limit State Function $G$ is obtained as presented in Figure 22. In this diagram, the portion that fulfills the condition $G<-t_{\text {margin, }}$ (the part in the figure painted in black) provides the probability where the Egress Time Margin takes a negative value in the building plan under consideration. The portion that provides $G<0$ (the parts in the figure painted in black and in gray) is the probability that the Egress Time Margin will become less than the Egress Time Margin that corresponds to the prescribed Design Points in the Verification Method. This, therefore, is the condition that corresponds to the Safety Level required in the Verification Method, and is called the Acceptable Probability of Failure $p_{f}$. Also, the value $B_{\text {target }}=\mu_{G} / \sigma_{G}$, obtained by dividing the mean value $\mu_{G}$ of $G$ by the standard deviation $\sigma_{G}$, is called the Target Safety Index $B$ (or $B_{\text {target }}$ ). 


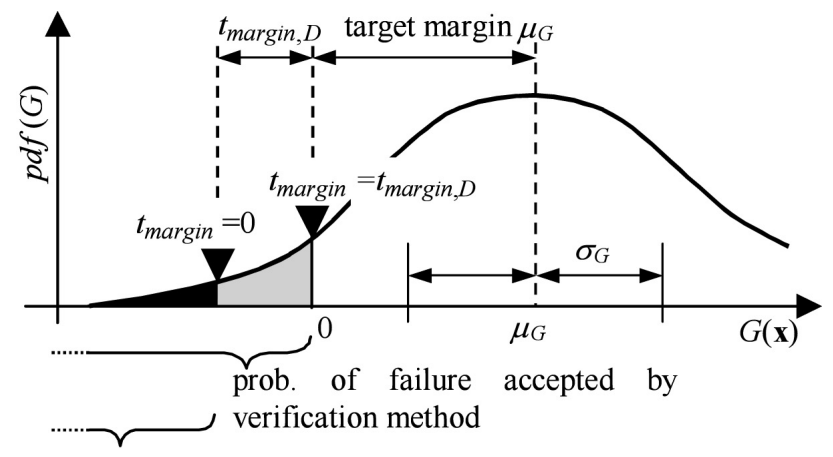

prob. of failure of a specific design solution

Figure 22 Distribution of the Limit State Function G and the Safety Level Required by the Verification Method

\subsubsection{Sensitivity of the Stochastic Variables and the Most Probable Failure Points}

In the analysis of Partial Safety Factor corresponding to the prescribed value of the Verification Method and the Probability of Exceedance (Section 3.3), we have pointed out that the Partial Safety Factors vary greatly by the variable. Since the configuration of the Partial Safety Factors is expected to have a large influence on the Safety Level that will finally be guaranteed in the Verification Method, the sensitivity of the Stochastic Variables against $G$ will be analyzed in this passage.

The sensitivity of the variables is obtained using the result of the Monte-Carlo simulation, and solving the normalization equation to evaluate the Regression Sensitivity Coefficient between $G$ and the input variable x. Regression Sensitivity Coefficient is given by the following equation:

$$
a_{i}=\frac{\partial\left(\mu_{G} / \sigma_{G}\right)}{\partial\left(\left(x_{i}-\mu_{x_{i}}\right) / \sigma_{x_{i}}\right)}
$$

Here, out of the input variables $\mathrm{x}$ defined in Equation (24), the $\mathrm{i}$-th element is expressed as $\mathrm{x}_{i}\left(x_{1}=p, x_{2}=q l, x_{3}=v, \cdots\right)$. Using $a_{i}$, the relative sensitivity (defined as the variance that arises in $G$ when a change equivalent to the standard deviation is acted on variable $\mathrm{x}_{i}$ alone divided by the total variance) is calculated using the following equation:

$$
a_{i}=\frac{\partial\left(\mu_{G} / \sigma_{G}\right)}{\partial\left(\left(x_{i}-\mu_{x_{i}}\right) / \sigma_{x_{i}}\right)}
$$

To obtain the Most Probable Failure Point, the elements of $G$ with negative values were depicted from the samples obtained in the Monte-Carlo simulation, and a MPFP was determined so that the sum of the square of the deviation from the mean value of the corresponding input values becomes the smallest:

$$
\beta_{M P F P}=\min \sqrt{\sum_{i}\left(\frac{x_{i}^{k}-\mu_{x i}}{\sigma_{x i}}\right)^{2}}
$$

Here, the suffix $k$ denotes the trial number in Monte-Carlo simulation. 


\subsection{Analysis of Room Evacuation}

\subsubsection{Categorization of Floor Plans of the Existing Office Building in Conjunction with Room Evacuation}

In the Verification Method, the variables that are related to safe evacuation from a fire room are: Floor Area $A_{\text {room }}\left[\mathrm{m}^{2}\right]$, Ceiling Height $H_{\text {room }}[\mathrm{m}]$, Number of Exit Doors $N_{\text {doors }}$ [-], Width of the Exits $B_{\text {room }}[\mathrm{m}]$, the Walking Distance to the Exit from the Furthest Location in the Room $l_{l}[\mathrm{~m}]$, and the Smoke Control Systems (No Ventilation (referred to as Smoke Filling System here after), Natural Ventilation System, and Mechanical Ventilation System). Therefore, by retrieving the design variables from the existing designs, it is possible to describe a typical floor plan. Concerning the floor plans of office buildings, the placement of the corridor has been categorized into several types [38]. In this study, the design parameters were read on the plans of the buildings with single side corridor as shown in Figure 23 available in the published plan [39-44] (18 rooms in 15 samples [Note8]), and the relations with the floor areas were studied. Since the two-dimensional shape of most of the rooms is rectangular, the ratio of the depth of the room to the width $(Y / X)$ was analyzed instead of taking the walking distance. Also, the sum of the Widths of the Exits were divided by $0.9 \mathrm{~m}$ and rounded off to be considered as the Number of Exit Doors $N_{\text {doors }}$.

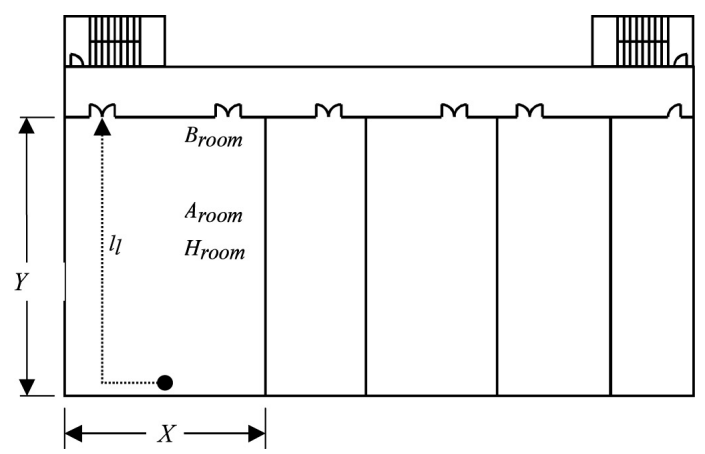

Figure 23 Model Floor Plan of an Office Building with Single-side Corridor

The results are shown in Figure 24 - 27. Figure 24 provides the dimensions (Width $X$ and Depth $Y$ ) of the surveyed rooms. In the figure, there are some smaller rooms with shapes close to a square, but the larger rooms tend to spread out wide along the outer rim of the building, as they cannot increase the depth for reasons such as sunlight intake. Figure 25 shows the relation between the ratio of the depth of the room to the width $(Y / X)$ and the floor area for the data used in Figure 24.

As shown in Figure 26, there is a certain degree of freedom in the number of exits for rooms with smaller floor areas, however, in larger rooms, the number of exits increases proportionally to the increase of the floor area. Therefore, it can be categorized as a pattern of rooms where the number of exits increases with the increasing width of the 
room. Considering the results shown in the Figure 25 and Figure 26, there is a tendency for a door to be placed at a certain width.

As for the ceiling height, it was anticipated that the value will increase as the floor area becomes larger in order to improve visual comfort. However, as shown in Figure 27 , the result obtained in this survey shows no significant relation between the two parameters.

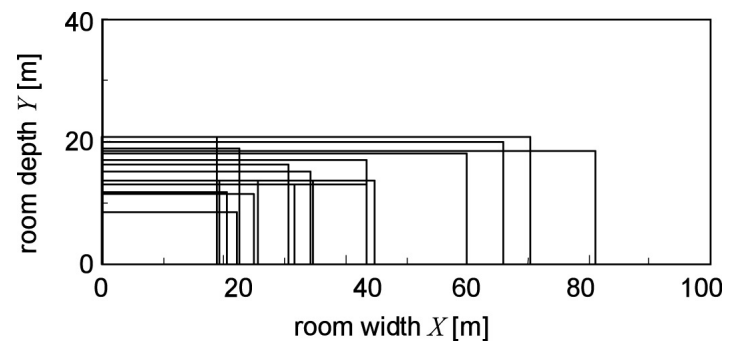

Figure 24 Typical Patterns of Floor Areas and Depths of the Rooms

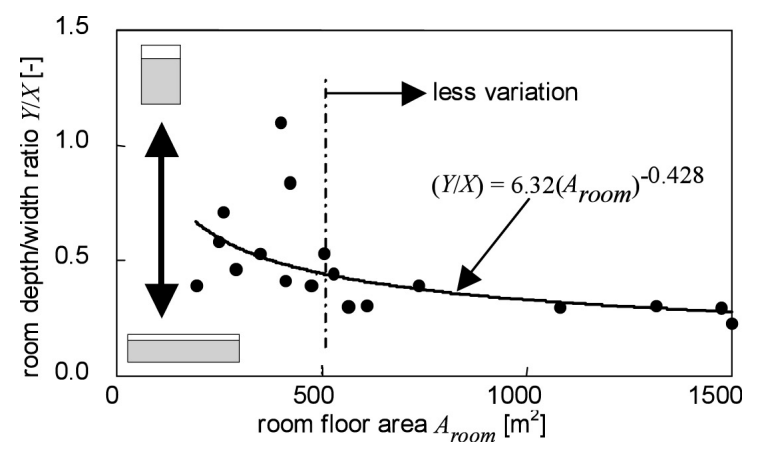

Figure 25 Relation between the Ratio of the Depth of the Room to the Width (Y/X) and the Floor Area $A_{\text {room }}$

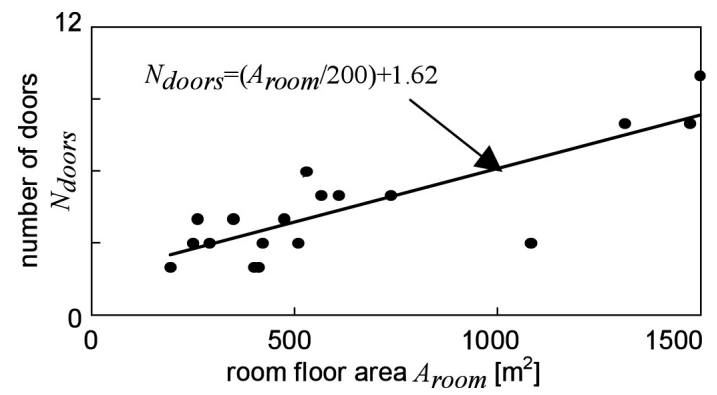

Figure 26 Relation between the Number of Exits and the Floor Area of the Room $A_{\text {room }}$ 


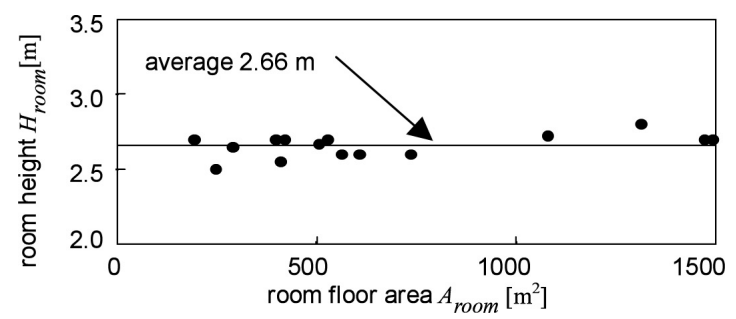

Figure 27 Relation between the Ceiling Height $H_{\text {room }}$ and the Floor Area of the Room $A_{\text {room }}$

\subsubsection{Conditions for Analysis of Room Evacuation}

In order to analyze the Safety Level requested by the Verification Method in room evacuation, the rooms are sorted into 3 types according to the smoke control system: Smoke Filling System, Natural Ventilation System, and Mechanical Ventilation System. For each category, Monte-Carlo simulation (Number of trials: 3000) was performed with the floor area in the range between $100-1500 \mathrm{~m}^{2}$.

The conditions will be configured as follows: for Type A variables $\left(p, q_{l}\right)$ and Type B variables $\left(v, N, t_{\text {start }}, \mathrm{a}_{f}, \mathrm{a}_{m}, t_{S}\right)$, the values presented in Table 1 in Section 3.3 according to the Probability Density Function ( $p d f$ ) will be used; for the design parameters, the values derived from the equation providing the relation with the floor area are used as presented in the previous section. Therefore, using the equation providing the relation between the ratio of the depth of the room to the width $(Y / X)$ shown in the Table 3, the Walking Distance $l_{l}$ will be determined as follows:

$$
l_{l}=Y+X / 2=X[(Y / X)+1 / 2]=[(Y / X)+1 / 2] \sqrt{\frac{A_{\text {room }}}{(Y / X)}}
$$

As for the width of the exit, the value is evaluated by substituting the value of the floor area into the equation giving the relation provided in Figure 26, and rounding off the value, then multiplying it by 0.9 .

The variation of the ceiling height is small. All the samples shown in Note 8 fell within the range of $2.50-2.80 \mathrm{~m}$, with one exception where the value was extremely large $(3.50 \mathrm{~m})$. Hence, a constant value, or the mean value $2.66 \mathrm{~m}$ was adopted. Also, it is difficult to obtain information on smoke ventilation-related parameters from the floor plans provided in the references. Therefore, the values shown in Table 4 are used, assuming that they follow the Technical Guideline on Smoke Control System [45]. Here, at least one doorway will be left open during the evacuation of the occupants, function as an air intake for smoke ventilation. The area of the opening was determined to be $1.8 \mathrm{~m}^{2}$ corresponding to a door. 
Table 3 Design Dimensions of a Typical Room in an Office Building with Single Side Corridor

\begin{tabular}{|l|l|c|}
\hline \multicolumn{1}{|c|}{ Design Dimension } & \multicolumn{1}{|c|}{ Relation with the Floor Area } & $\begin{array}{c}\text { Number of } \\
\text { Samples }\end{array}$ \\
\hline \hline Ratio between depth and width $(Y / X):$ & $(Y / X)=6.32 A_{\text {room }}-0.428[-]$ & \multirow{2}{*}{18} \\
\cline { 1 - 2 } Number of Exits & $\begin{array}{l}N_{\text {doors }}=\left(A_{\text {room }} / 200\right)+1.62[-] \\
\text { (round off to the single digit })\end{array}$ & - \\
\hline Width of the exit & $B_{\text {room }}=0.9 N_{\text {doors }}[-]$ & 15 \\
\hline Height of the ceiling & $H_{\text {room }}=2.66[\mathrm{~m}]$ & \multirow{2}{*}{} \\
\hline
\end{tabular}

Table 4 Design Dimensions Concerning Smoke Control System

\begin{tabular}{|l|l|}
\hline Design Dimension & Relation with the Floor Area $A_{\text {room }}$ \\
\hline (Natural Ventilation System) & \\
Effective area of the opening for smoke ventilation $\left[\mathrm{m}^{2}\right]$ & $A_{\text {room }} / 50$ \\
Height of the smoke ventilation opening & $0.5 \mathrm{~m}$ \\
Effective area of the air intake $\left[\mathrm{m}^{2}\right]$ & $(0.9 \times 2.0) \mathrm{m}^{2}$ \\
\hline (Mechanical Ventilation $S y s t e m)$ & \\
Flow rate for ventilation $\left[\mathrm{m}^{3} / \mathrm{min} / \mathrm{m}^{2}\right]$ & $1.0 A_{\text {room }}$ \\
\hline
\end{tabular}

\subsubsection{Result of the Analysis of Target Safety Index $\beta_{\text {target }}$ and Acceptable Probability of Failure $p_{f}$ for Room Evacuation}

In order to consider the influences of Type A and Type B variables separately, two types of analysis are conducted: one where stochastic input is adopted on Type A variables only; and the other where stochastic input is adopted on both Type A and Type $B$ variables.

\section{(1) Cases where stochastic input is adopted on Type A variable only}

The Figure 28 and Figure 29 show the results for an example with a floor area of $180 \mathrm{~m}^{2}$, ceiling height of $2.66 \mathrm{~m}$, no smoke ventilation (Smoke Filling System), and with three exits each of $90 \mathrm{~cm}$ width.

Figure 28 shows the result of calculation in the case that stochastic input is adopted for Type A variables, and deterministic input for Type B variables using the values prescribed in the Verification Method. As shown in the figure, Egress Time Margin (nominal margin) at the prescribed Design Point in the Verification Method is 0.052 minutes. This design condition conforms the requirement of the Verification Method.

Seeing the distribution of the Limit State Function, trimming the design so that the value of the Egress Time Margin at the Design Point prescribed in the Verification Method gives zero will still provide a remaining Egress Time Margin of 0.394 minutes at the mean value $\mu_{G}$. The standard deviation $\sigma_{G}$ of $G$ is 0.115 minutes, therefore the safety index will be 3.87, and the probability that the value of $G$ will become negative (the probability of a value lower than the Egress Time Margin at the prescribed Design Point) will be $0.26 \%$. 
Figure 29 is calculated against the same design values; however the mean values are used for Type B variables instead of the prescribed values. The mean value of $G\left(\mu_{G}\right)$ gave 1.56 minutes and the Target Safety Index gave 6.69. The numeric was considerably large compared with the case using the prescribed values. From the 3000 trials, no cases were seen where $G$ took a negative value, so the Probability of Failure will be $0.033(=1 / 3000) \%$ or less. The only differences between Figure 28 and Figure 29 were the values of Type B variables, in other words, it can be said that the Target Safety Level is strongly dependent on the set values of Type B variables.

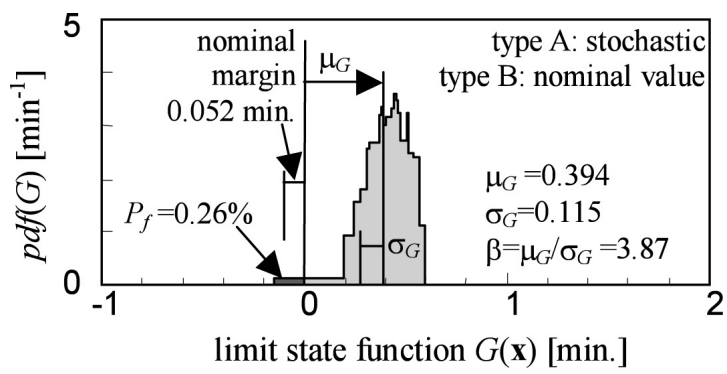

Figure 28 Distribution of the Limit State Function

(floor area $180 \mathrm{~m}^{2}$, ceiling height $2.66 \mathrm{~m}$, no ventilation, exit width $90 \mathrm{~cm} \times 3$ locations, Type $A$ variables $=$ stochastic input, Type $B$ variables $=$ nominal input of prescribed values)

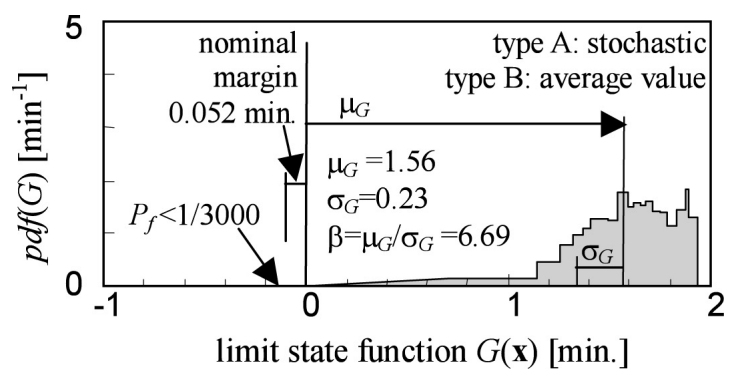

Figure 29 Distribution of Limit State Function (design conditions are equivalent to Figure 28. Type A variables = stochastic input,

Type $B$ variables $=$ nominal input of mean values)

A similar calculation was performed altering the floor area from $100 \mathrm{~m}^{2}$ to $1500 \mathrm{~m}^{2}$. Figure 30 shows the result when Smoke Filling System was adopted for the Smoke Control System. Target Safety Index was between 5.4 - 6.9 when the prescribed values were used for Type B variables, whereas the values were between 1.5 - 3.9 when the mean values were used for Type B variables. There is a difference of around 3 between the two results, which implies that the Safety Level depends greatly on the selection of Type B variables. This is also apparent from the comparison of the Acceptable Probability of Failure. When the prescribed values were used for Type B variables, Acceptable Probability of Failure tended to increase with the floor area, and rose to $8 \%$ when the floor area reached $1500 \mathrm{~m}^{2}$. On the other hand, when the mean values were used, Probability of Failure remained almost at zero. 


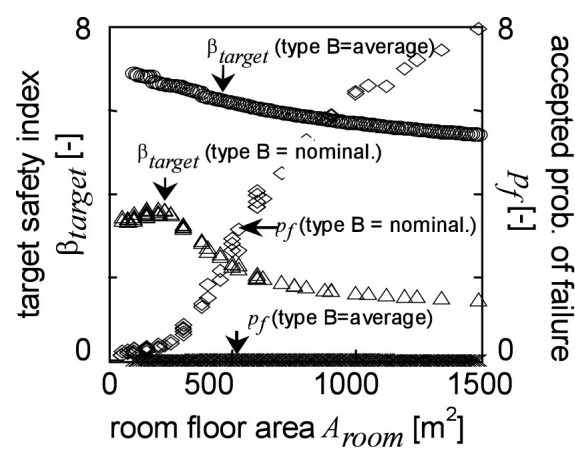

Figure 30: Target Safety Level in Evacuation from a Room with Smoke Filling System (prescribed values or mean values for the Type B variables)

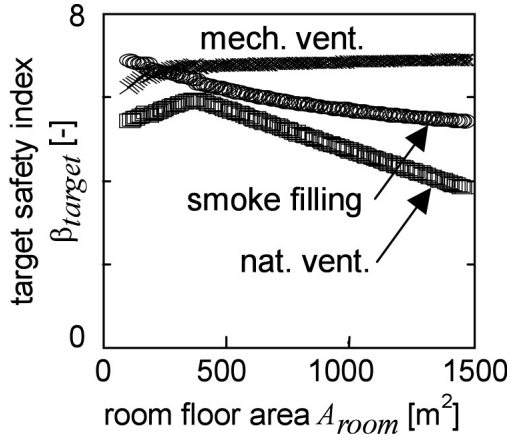

Figure 31: Target Safety Level in Evacuation from a Room grouped according to the Smoke Control System (mean values for Type B variables)

Figure 31 shows the Target Safety Index when the mean values are used for Type B variables, sorted according to the Smoke Control System. Although the figures have been omitted in this paper, the Acceptable Probability of Failure took values close to zero regardless of the type of Smoke Control System used. Except for in the region where the floor area of the room is small, the value of the Target Safety Index increases in the following order according to the type of Smoke Control System adopted: Natural Ventilation System, Smoke Filling System and Mechanical Ventilation System. The value of Target Safety Index takes a near-constant level in rooms adopting Mechanical Ventilation System. On the other hand, in situations where a Smoke Filling System or Natural Ventilation System is adopted, the value of Target Safety Index tends to drop as the floor area becomes large. Especially in the case of a Natural Ventilation System where the value tends to rise until the floor area reaches $400 \mathrm{~m}^{2}$, and then drops off as the area becomes larger [Note 9].

\section{(2) Cases where stochastic input is adopted on both Type A and Type B variables}

It is shown through the analysis in the previous section, that the Target Safety Level has a large dependency on Type B variables. Therefore, in this section, stochastic input is adopted on both Type A and Type B variables, and the distribution of Limit State Function is calculated in order to analyze the characteristics of the finally guaranteed Target Safety Index and the Acceptable Probability of Failure.

Figure 32 shows the distribution of the Limit State Function obtained by adopting stochastic input for both Type A and Type B variables in the same building plan as the one used for Figure 28 and 29 in the previous section. The mean value in this figure is 1.91 minutes, which is not far off from the result obtained in Figure 29 where mean values are used for Type B variables. However, the standard deviation of 1.15 minutes is much larger than the corresponding value in Figure 29. Therefore, the variation of the Egress Time Margin is greatly amplified by the variation of Type B variables, and the Target Safety Index will be considerably smaller compared with the case when nominal 
input of mean values is adopted for Type B variables (Figure 10), yielding results closer to the case when nominal input of the prescribed values in the Verification Method is adopted for Type B variables (Figure 28).

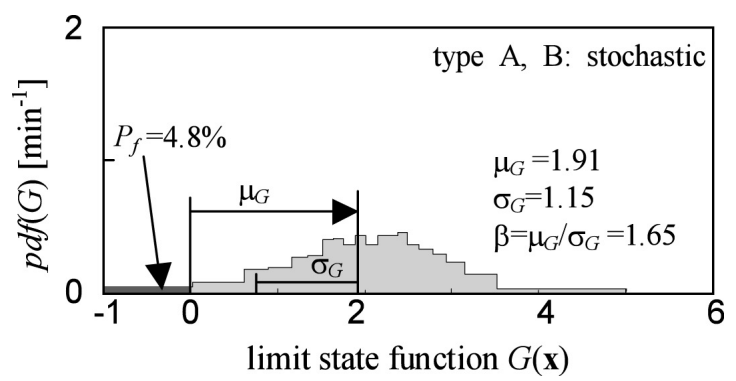

Figure 32 Distribution of Limit State Function

(Design conditions are equivalent to Figure 28. Type A and Type B variables = stochastic input)

Figure 33 shows the changes in Target Safety Index and Acceptable Probability of Failure following the changes in the floor area for each Smoke Control System. Regardless of the Smoke Control System, the dependency of the Target Safety Index to the floor area is not significant. The degree of dependence differs according to the Smoke Control System: Mechanical Ventilation System, Smoke Filling System, and Natural Ventilation System (in an ascending order). For Smoke Filling System, the Acceptable Probability of Failure takes a near-constant value at approximately 5\%, whereas, in Natural Ventilation System and Mechanical Ventilation System, the Acceptable Probability of Failure tends to become smaller as the floor area becomes larger.

Also, comparing the result for Smoke Filling System in Figure 33 with Figure 30, Target Safety Index will be considerably smaller than when the nominal input of mean values is adopted for Type B variables, and is rather close to when the nominal input of the prescribed values in the Verification Method is selected. This tendency coincides with the previous explanation for Figure 28, 29, and 32.

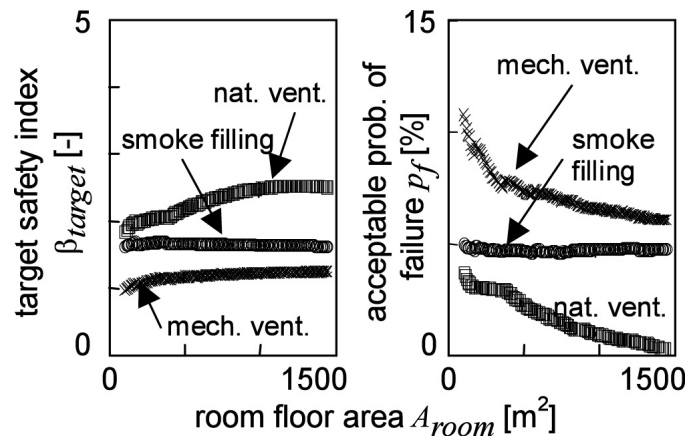

Figure 33 Target Safety Level and Acceptable Probability of Failure when stochastic input are adopted for both Type A and Type B variables 


\subsubsection{Consideration on the Sensitivity of the Stochastic Variables and the Most Probable Failure Point in Room Evacuation}

The results obtained in the previous section for the case when stochastic input is adopted for both Type A and Type B variables were analyzed in order to examine the sensitivity of the variables and the MPFP. Figure 34 is the relative sensitivity obtained by applying Equation (27) to the samples in the Monte-Carlo simulation derived in the calculation for Figure 33. The figures show the sensitivities for the following three variables: Fuel Load Density $q_{l}$, Compensating Rate for Egress Start Time $f_{\text {start }}$, and Compensating Rate for Smoke Filling Time $f t_{S}$. The relative sensitivity of the other variables is practically zero, and each of the variation of these variables will pose no significant influence on the variation of the Limit State Function $G$.

The sensitivity of the Egress Start Time is dominant in a Smoke Filling System, and the sensitivity of the Smoke Filling Time is dominant in a Mechanical Ventilation System. The sensitivity of Fuel Load Density is relatively large in a Natural Ventilation System. Therefore, in order to perform a deterministic evaluation using the Verification Method, it is extremely important to set the three input values appropriately.
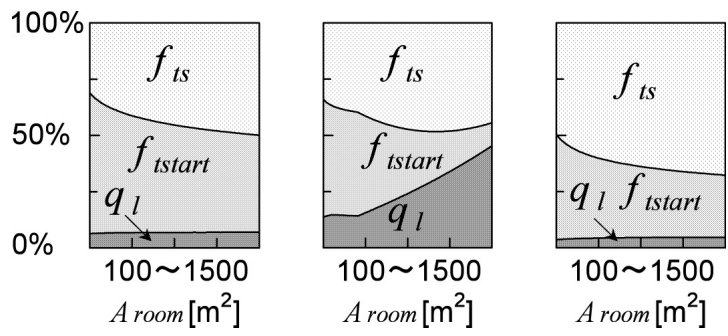

(i) Smoke Filling System (ii) Natural Ventilation System (iii) Mechanical Ventilation System

Figure 34: Relative Sensitivity of the Input Variables

In order to maintain the Safety Level that is to be achieved, it is recommended to configure the input values near the MPFP. Therefore, the MPFP is depicted from the result of the simulations according to Equation (28), and the values of the input variables corresponding to the MPFP are organized. The results are shown in Figures 35 37 using non-dimensional Partial Safety Factor.

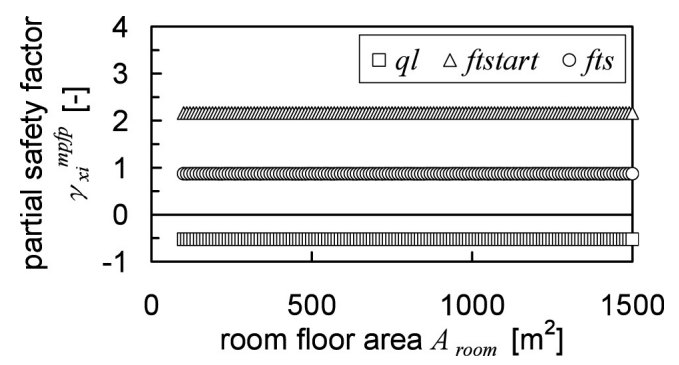

Figure 35 Partial Safety Factor at the MPFP (Smoke Filling System) 


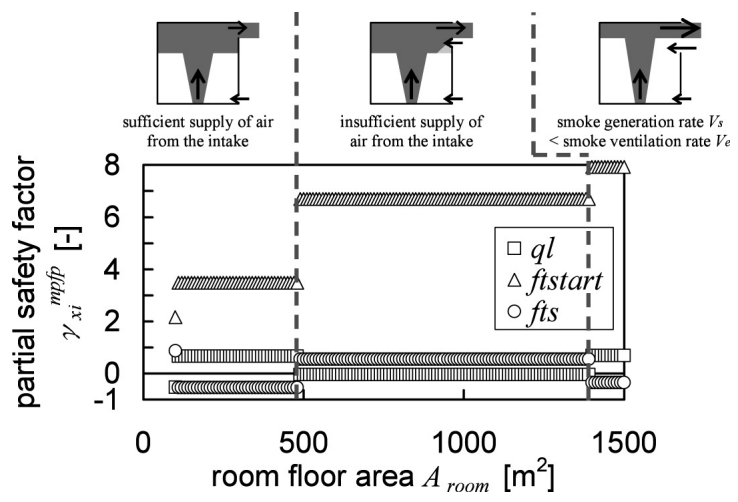

Figure 36 Partial Safety Factor Corresponding to the MPFP (Natural Ventilation System)

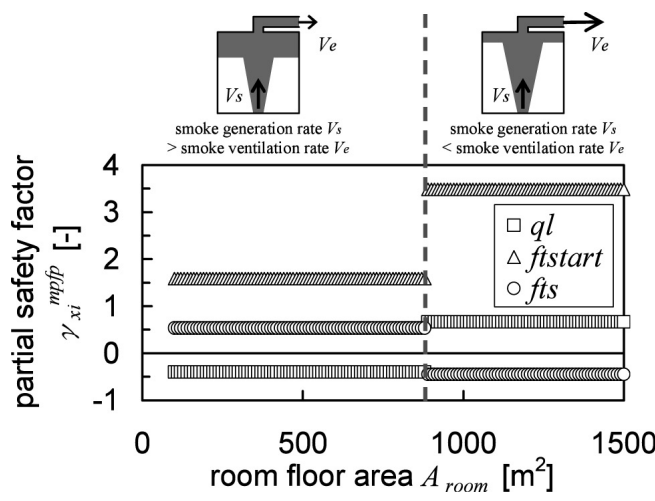

Figure 37 Partial Safety Factor Corresponding to the MPFP (Mechanical Ventilation System)

In a Smoke Filling System, the Partial Safety Factor of the three Stochastic Variables corresponding to the MPFP show no dependence on the size of the floor. On the other hand, the Natural Ventilation System and the Mechanical Ventilation System poses a dependence with different characteristics with respect to each region of the floor area. Investigating the reason for these characteristics, it was observed that in a room adopting Natural Ventilation System the influential factors were the ratio of the area of the air intake against the area of the opening for smoke ventilation and the ratio of smoke ventilation against generation of smoke. Likewise, in a room adopting Mechanical Ventilation System, it was found that the ratio of smoke ventilation against generation of smoke was influential. With regards to these conditions, the representative values for each Smoke Control System obtained are shown in Table 5. Therefore, it can be said that appropriate values can be obtained for each of the stochastic variables by adding a certain value to the mean value. These values are around 0.7 times the value of the standard deviation for Fuel Load Density, around 2 to 8 times the value of the standard deviation for Egress Start Time, and around 0.9 times the value of the standard deviation for Smoke Filling Time respectively. 
Table 5 Comparison of the Partial Safety Factors for the Stochastic Variables $\gamma^{M P F P}$ and $\gamma^{D}$

\begin{tabular}{|c|c|c|c|c|c|c|}
\hline \multirow{2}{*}{ Smoke Control System } & \multicolumn{2}{|c|}{$q l$} & \multicolumn{2}{|c|}{$f_{t_{\text {start }}}$} & \multicolumn{2}{|c|}{$f t s$} \\
\hline & $\gamma^{M P F P}$ & $\gamma^{D}$ & $\gamma^{M P F P}$ & $\gamma^{D}$ & $\gamma^{M P F P}$ & $\gamma^{D}$ \\
\hline Smoke Filling System & -0.53 & \multirow{6}{*}{4.97} & 2.16 & \multirow{6}{*}{-0.383} & 0.87 & $2.23 *)$ \\
\hline \multirow{3}{*}{$\begin{array}{l}\text { Natural Ventilation } \\
\text { System } * *)\end{array}$} & 0.67 & & 3.49 & & -0.54 & \multirow{3}{*}{2.87} \\
\hline & -0.04 & & 6.70 & & 0.55 & \\
\hline & 0.69 & & 7.93 & & -0.35 & \\
\hline \multirow{2}{*}{$\begin{array}{l}\text { Mechanical Ventilation } \\
\text { System***) }\end{array}$} & -0.40 & & 1.59 & & 0.54 & \multirow{2}{*}{1.37} \\
\hline & 0.67 & & 3.49 & & -0.45 & \\
\hline
\end{tabular}

[Table notation]

MPFP = Partial Safety Factor corresponding to Most Probable Failure Point. D= Partial Safety Factor corresponding to the prescribed value in the Verification Method.

*) Value corresponding to $A_{\text {room }}=500 \mathrm{~m}^{2}$

**) For Natural Ventilation System, each block represents the following condition: Upper block - air intake from inlet is sufficient, middle block - air intake from inlet is insufficient, bottom block - smoke ventilation exceeds generation of smoke.

***) For Mechanical Ventilation System, each block represents the following condition: Upper block - generation of smoke exceeds smoke ventilation, bottom block - smoke ventilation exceeds generation of smoke.

\subsection{Analysis of Floor Evacuation}

\subsubsection{Categorization of Floor Plans of the Existing Office Building in Conjunction with Floor Evacuation}

Theoretically there are infinite combinations of building design parameters such as the floor areas of the rooms and floors, number of exits from the rooms and staircases, and so on. However, if the usage of the buildings and the basic plans can be restricted, categorization is possible to a certain extent. Concerning the floor plans of office buildings, the placements of the corridors and the staircases are categorized into several types[38]. For floor evacuation, as in the case of room evacuation, typical 28 standard floors in 26 cases [39-44] are selected from existing office buildings as the standard floor plan of buildings with single side corridor. The building design parameters to be entered in the Verification Method are investigated and categorized against these samples [Note 10].

The parameters concerning safe evacuation from a fire room has already been explained in Section 4.2.1, therefore, in this section, we will provide some results concerning the building design parameters related to safe evacuation from a fire floor.

Figure 38 shows a floor plan of a building with a single side corridor. The building design parameters concerning safe evacuation from a fire floor are: total floor area of the rooms $A$ load $\left[\mathrm{m}^{2}\right]$, number of rooms on the floor under consideration $N_{\text {rooms }}$, the maximum and minimum floor areas of a room $A_{\text {room,max }}$ and $A_{\text {room,min }}\left[\mathrm{m}^{2}\right]$, the walking distance to the staircase from the furthest location in the room $l_{l}[\mathrm{~m}]$, floor area of the 
corridor $A_{c o}\left[\mathrm{~m}^{2}\right]$, number of escape staircases $N_{S t}$, total floor area of the escape staircases $A_{s t}\left[\mathrm{~m}^{2}\right]$, total width of the doors separating the rooms from the corridor $B$ load $[\mathrm{m}]$, total of the width of the exits to the staircases $B_{S t}[\mathrm{~m}]$, and the ceiling height $H_{\text {room }}[\mathrm{m}]$.

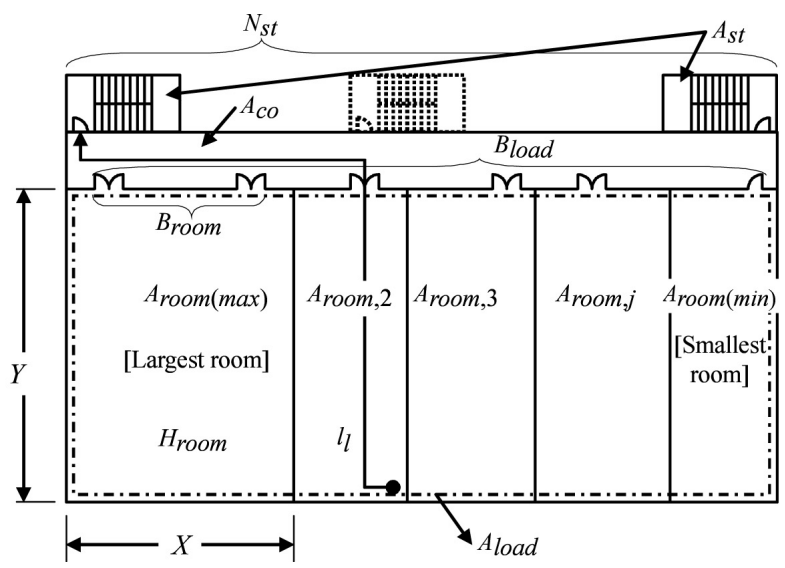

Figure 38 Model Floor Plan with Single Side Corridor (parts related to safe evacuation from a fire floor)

\section{(1) Ratio between the Number of Rooms and Floor Area}

Figure 39 shows the relation between the number of rooms and the floor area for all 28 standard floor plans examined. The tendency of room division shows changes at $1500 \mathrm{~m}^{2}$, which is the upper limit of a single fire compartment. Floors with a total room floor area smaller than $1500 \mathrm{~m}^{2}$ tend to use the floor as a single room. On the other hand, samples with total floor area of the room of over $1500 \mathrm{~m}^{2}$ tend to divide the floor into multiple rooms. Figure 39, the dotted line shows the $1,500 \mathrm{~m}^{2}$ line that divide the diagram into two blocks, and the fractions show the rate of appearance within each block [Note 11].

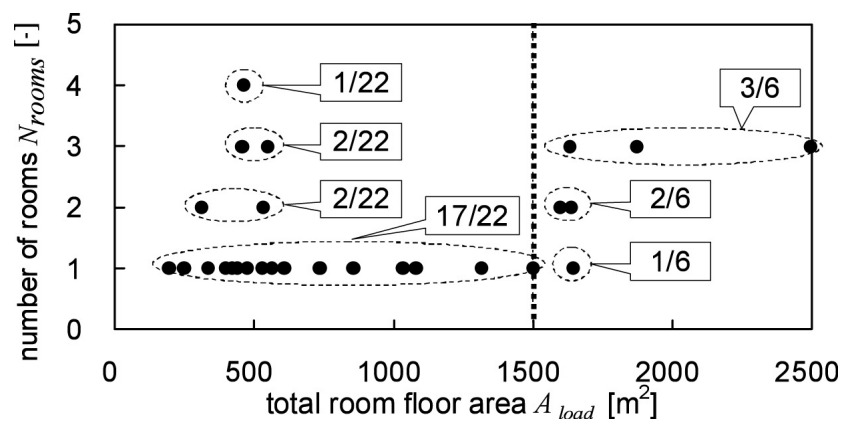

Figure 39 Relation Between the Number of Rooms Nrooms and the Total Area of Room Floor Aload[m²]

When the floors are divided, it is rather rare that they will be divided into rooms with the same floor area. Figure 40 shows the ratio of the floor area when the floor is divided into 2 to 4 rooms. As this figure show, the relation between the maximum floor area of the room $A_{\text {room,max }}$ and the minimum floor area of the room $A_{\text {room, min }}$ are given with the following equation: When the floor is divided into four rooms, it is considered that 
the floor area of the two remaining rooms will be divided evenly.

(when the floor is divided into two rooms)

$$
\begin{aligned}
& A_{\text {room }, \text { max }} / A_{\text {load }}=1-A_{\text {room }, \mathrm{min}} / \text { Aload } \\
& A_{\text {room }, \min } / A_{\text {load }}=9.68 \times 10^{-5} \text { Aload }+0.019
\end{aligned}
$$

(when the floor is divided into three rooms)

$$
\begin{aligned}
& A_{\text {room }, \text { max }} / \text { Aload }=0.859-2.10 \times 10^{-4} \text { Aload } \\
& A_{\text {room }, \text { min } / A_{\text {load }}=1.17 \times 10^{-4} A \text { load }}-0.0189
\end{aligned}
$$

(when the floor is divided into four rooms)

$$
\begin{aligned}
& A_{\text {room }, \text { max }} / A_{\text {load }}=0.32 \\
& A_{\text {room }, \min } / A_{\text {load }}=0.21
\end{aligned}
$$
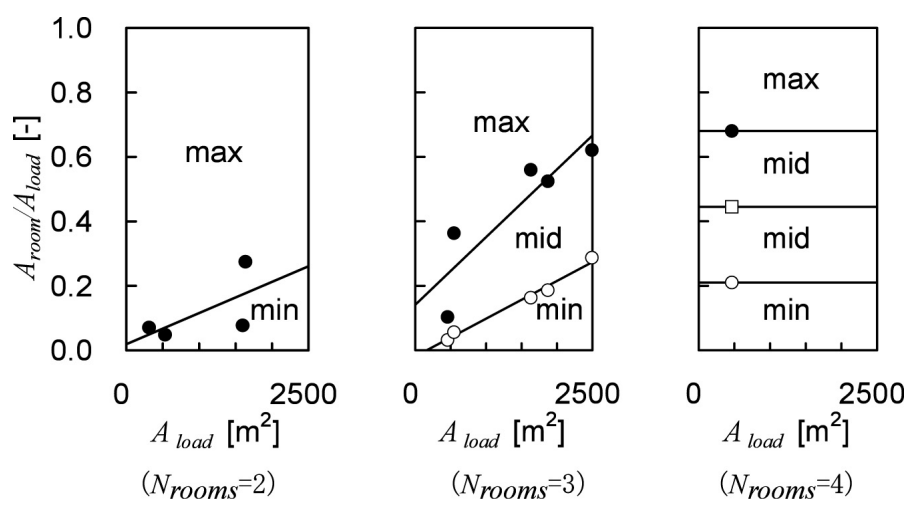

Figure 40 The Division Ratio of the Room Floor

\section{(2) Floor Area of the Corridor}

The result of the survey on the floor area of the corridor is shown in Figure 41. When the total floor area of the rooms is small, the floor area of the corridor is extremely small, and there are cases in buildings with floor areas of $200 \mathrm{~m}^{2}$ or less, where there is scarcely any corridor at all. The area of the corridor will increase with the total floor area of the room. However the samples tend to split into two groups: those that reserve plenty of corridor space; and those that cut down on the corridor space, and the gap between the two groups is not small. 


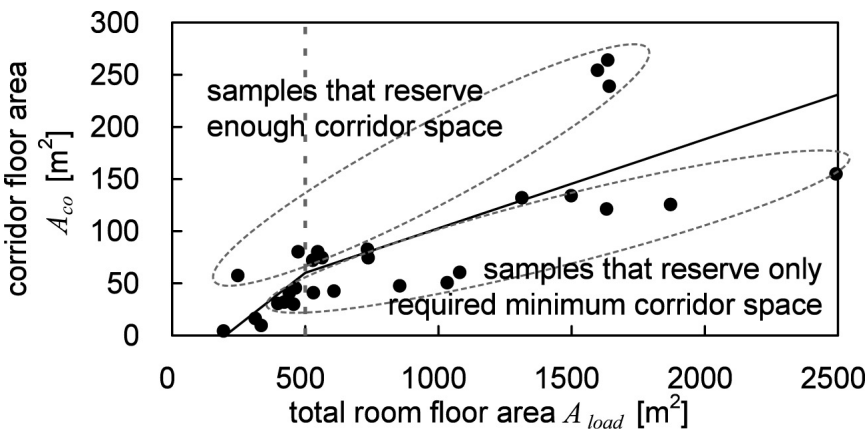

Figure 41 Corridor Floor Area

Here, the average between the two groups is adopted, and the relation with the total floor area of the room will be presented with the next equation:

$$
A_{C O}= \begin{cases}0 & \left(A_{\text {load }}<200\right) \\ 0.2 A_{\text {load }}-40 & \left(200 \leq A_{\text {load }}<500\right) \\ 0.085 A_{\text {load }}-17.25 & \left(500 \leq A_{\text {load }}\right)\end{cases}
$$

\section{(3) Walking Distance from the Furthest Location}

Figure 42 shows the walking distances from the furthest point in the room to the door leading to the escape staircase ( $l_{l}$ in Figure 23) for the samples. The walking distance tends to increase as the total floor area of the room increase, and the relation can be roughly approximated with the following equation:

$$
l_{l}=1.30 \sqrt{A_{\text {load }}}
$$

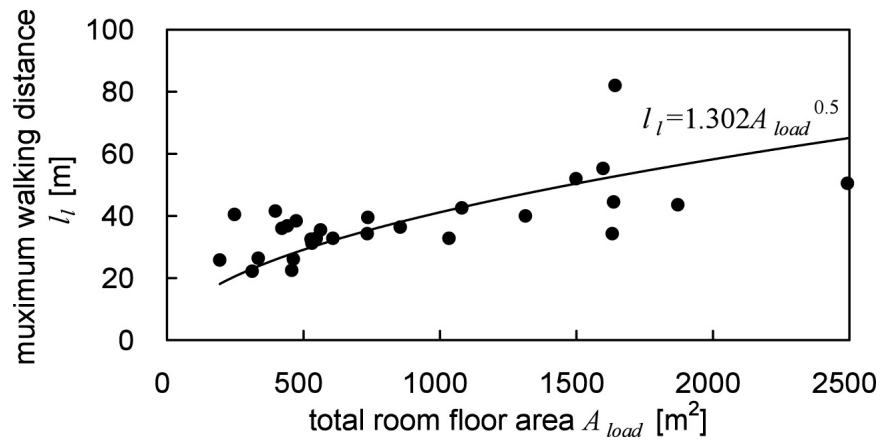

Figure 42 Walking Distance from the Furthest Location

\section{(4) The number of escape staircases, floor area of the staircase}

Figures 43 and 44 show the results of the survey on the number of escape staircases and their total floor area. With the exception of smaller cases, many buildings have two escape staircases, and there are some cases where there are 3 to 4 escape staircases. Although the exact width of the exit to each staircase could not be distinguished from 
the surveyed building plans that provided the source of information for Figures 43 and 44 , escape staircases with larger floor area tend to have doors with wider width leading to them. Therefore, the total floor area of the escape staircases is calculated for each sample in order to define the floor area per a location of escape staircase as an average of $14.7 \mathrm{~m}^{2}$ obtained from the result of this survey. The number of staircases was derived using the following equation so that the total width of the exit leading to the staircase will match this result [Note 12].

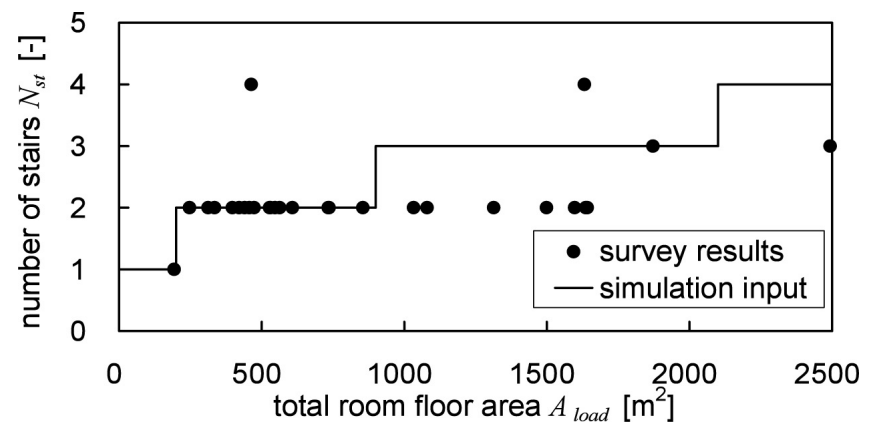

Figure 43 Number of Escape Staircases

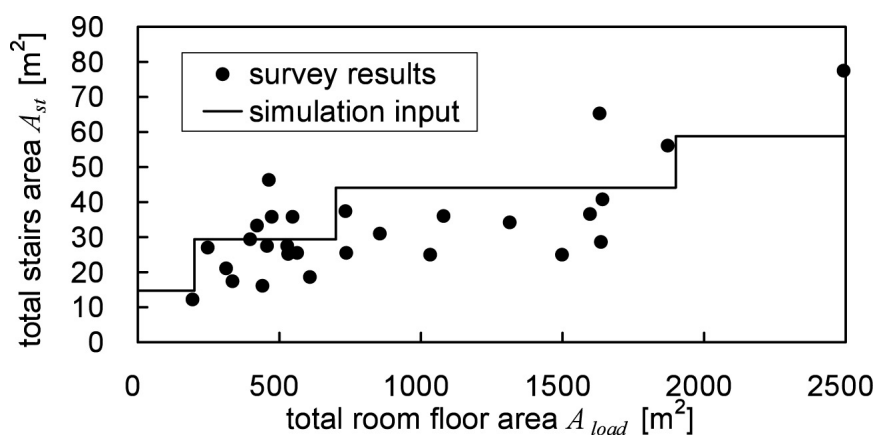

Figure 44 Total Floor Area of Escape Staircases

$$
N_{s t}=0.147 A_{\text {load }}^{0.402}
$$

Therefore, the decimal points of Equation (38) are rounded up to provide the value of $N_{S t}$ as an integer:

$$
A_{s t}=14.7 N_{s t}
$$

Also, the width of the exit was defined as 0.9 meters per exit.

\section{(5) Design parameters concerning smoke ventilation}

Although the smoke ventilation-related design parameters cannot be retrieved from the publicized floor plans, the following three types of situations are assumed: when Mechanical Ventilation System or Natural Ventilation System is installed according to 
the Technical Guideline on Smoke Control System [45], and when Smoke Filling System is adopted. The parameters will be configured with the values used in the evaluation of room evacuation, i.e. equivalent to the values shown in Table 4, Section 4.2.2. Note here, that one door will be selected because at least one door is expected to be open during the evacuation as an air intake corresponding to the smoke ventilation. The effective area of that opening is defined as $1.8 \mathrm{~m}^{2}$.

\section{(6) Design parameters related to room evacuation}

In considering the evacuation from the fire floor, the evacuation from the fire room must be considered in the preceding phase. The parameters concerning room evacuation will be provided by Table 3, Section 4.2.2.

\subsubsection{Conditions for the Analysis of Floor Evacuation}

The floor to be considered is a standard floor of a building with single side corridor as shown in Figure 38. The total floor area of the room Aload will be varied in the range of $200-3000 \mathrm{~m}^{2}$, and the analysis will be performed under the following conditions.

The corridor will have a good look out. Since the occupants on the floor are considered to be awake, the information that the occupants of the fire room have escaped from their room will reach the other rooms.

It is assumed that the door between the rooms and the corridor will be a fire door without the performance of protection against smoke leakage [Note 13]. This implies that the fire will not spread through the fire doors before the escape from a fire floor is completed; therefore the Time Limit of Evacuation is determined as the time until the smoke that has gotten out of fire room through the gap of boundary around the doors covers the corridor down to a certain height.

Under this assumption, Monte-Carlo simulation is performed according to the procedure shown in Table 6. First, the total floor area of the room Aload is fixed as a condition of the calculation. Next, the building design parameters such as the number of rooms the floor is divided into, the floor area of the corridor, the number of staircases, and so on are calculated according to the correlation equations derived in Sections 4.2.1 and 4.3.1. Hence, the design of the building is fully determined. Next, Monte-Carlo simulation is performed according to the following procedures 1) - 9). 1) For one trial, select the fire room based on probability according to the ratio of the floor area of the room against the total floor area of rooms on floor. 2) Type A and Type B variable is sampled randomly according to the Probability Density Function ( $p d f$ ) derived in Section 3.3. 3) As shown in Equation (7) of Section 3.2, the Egress Start Time from the selected fire room is obtained by multiplying the value obtained using the calculation equation for the Egress Start Time prescribed in the Verification Method by the Compensating Rate $f_{\text {tstart }}$.

$$
\begin{aligned}
& t_{\text {start }}=f_{\text {tstart }} \sqrt{A_{\text {room }}} / 30 \\
& f_{\text {tstart }}=\log \operatorname{Normal}(2.0,2.61)
\end{aligned}
$$


Table 6 Calculation Procedure

\begin{tabular}{|c|c|c|c|}
\hline \multicolumn{3}{|c|}{ Article } & Calculation Equation, etc. \\
\hline \multicolumn{2}{|c|}{$\begin{array}{l}\text { Configuration of total floor area of the room } \\
\left(A_{\text {load }}\right)\end{array}$} & & (Configured as the conditions) \\
\hline \multicolumn{2}{|c|}{$\begin{array}{l}\text { Configuration of building plan parameters: } \\
\text { number of rooms on the floor, floor area, } \\
\text { number of staircases, walking distance } \\
\text { from the furthest location, etc. }\end{array}$} & 曲 & $\begin{array}{l}\text { Relational expression with } A_{\text {load }} \\
\text { (Section } 4.3 .1(1) \text { ) }\end{array}$ \\
\hline \multirow{9}{*}{ 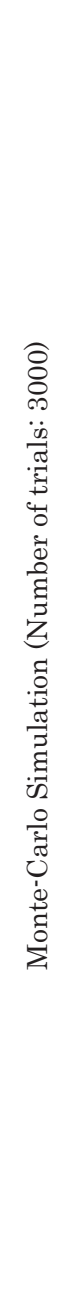 } & 1) Configuration of the fire room & 同 & $\begin{array}{l}\text { Fire room is selected according } \\
\text { to the ratio shown in Figure } 39\end{array}$ \\
\hline & $\begin{array}{l}\text { 2) Sampling of the stochastic } \\
\text { variables }\end{array}$ & & See Section 3.3 \\
\hline & $\begin{array}{l}\text { 3) Egress Start Time of the fire } \\
\text { room }\end{array}$ & \begin{tabular}{|l|l|} 
& \\
$\because \because$ \\
$\times:$ & $\because$ \\
\end{tabular} & Equations (40) and (41) \\
\hline & $\begin{array}{l}\text { 4) Time to Evacuation from the fire } \\
\text { room }\end{array}$ & \begin{tabular}{|l|l|} 
& $\because \because 6$ \\
$\times$ & $\bullet$ \\
\end{tabular} & $\begin{array}{l}\text { Same as in the Verification } \\
\text { Method (variables are randomly } \\
\text { sampled) }\end{array}$ \\
\hline & $\begin{array}{l}\text { 5) Egress Start Time of a room (not } \\
\text { the fire room) }\end{array}$ & \begin{tabular}{|l|l|} 
& $\because$ \\
& $\bullet$ \\
\end{tabular} & $\begin{array}{l}\text { Mean values of Egress Start } \\
\text { Time and Time to Evacuation of } \\
\text { the fire room }\end{array}$ \\
\hline & $\begin{array}{l}\text { 6) Time to Evacuation from the floor } \\
t_{e}\end{array}$ & Fifitifer & $\begin{array}{l}\text { Same as in the Verification } \\
\text { Method (variables are obtained } \\
\text { by random sampling) }\end{array}$ \\
\hline & $\begin{array}{l}\text { 7) Calculation of the Smoke Filling } \\
\text { Time of the fire room (time until the } \\
\text { smoke leaks out to the corridor) }\end{array}$ & & $\begin{array}{l}\text { Same as in the Verification } \\
\text { Method (variables are obtained } \\
\text { by random sampling) }\end{array}$ \\
\hline & $\begin{array}{l}\text { 8) Smoke Filling Time } t_{S} \text { of the } \\
\text { corridor }\end{array}$ & $\curvearrowright$ & $\begin{array}{l}\text { Same as in the Verification } \\
\text { Method (variables are obtained } \\
\text { by random sampling) }\end{array}$ \\
\hline & \multicolumn{3}{|l|}{ 9) Egress Time Margin: $t_{\text {margin }}=t_{s}-t_{e}$} \\
\hline 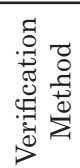 & \multicolumn{3}{|c|}{ Nominal Egress Time Margin: $t_{\text {margin }, D}=t_{s, D^{-}} t_{e, D}$} \\
\hline
\end{tabular}


4) The time to evacuation from the fire room is determined in the manner similar to the calculation equations prescribed in the Verification Method, which is defined as the time required to pass through the room exit added to the time required to walk to room exit. Here, the Walking Velocity $v$ and the Flow Rate $N$ is determined by using the method of random sampling. As for the Egress Start Time from the rooms other than the fire rooms, we considered that the noise of the occupants from the fire room will reach quickly to the other rooms as well, since the lookout is fine on a floor with single side corridor. Therefore, considering that the occupants start to evacuate from the non-fire rooms at half way point between time when the occupants start to evacuate from the fire room and time when they finish the evacuation from there, the Egress Start Time of non-fire rooms was derived as half time of the sum of the Egress Start Time of the fire room and the Time to Evacuation from there. 6) Time to Evacuation from the fire floor is measured as the time until every occupant has entered the escape staircase, which is obtained by adding the time to walk to the staircase and the time required to pass through the exit leading to the staircase to the Egress Start Time. Here again, the Walking Velocity $v$ and the Flow Rate $N$ is determined by a random sampling method instead of the prescribed value in the Verification Method. The calculation formula prescribed in the Verification Method is used for the Smoke Filling Time 7), 8). In the calculation, $q l$ and $\alpha_{m}$ are determined by a random sampling method, and the equations for $\alpha_{f}$ and $t_{S}$ are multiplied by the Compensating Rate $f \alpha_{f}$ and $f_{t s}$ randomly sampled according to $p d f$ obtained in Section 3.2.

From this calculation, the Egress Time Margin is obtained for each trial. The distribution of the probability density of the Floor Egress Time Margin is obtained by repeating this operation 3000 times. On the other hand, applying the Verification Method itself to the configured building plan, and obtaining in advance the nominal value of the Floor Egress Time Margin independent of the calculation above, and subtracting it from the Floor Egress Time Margin obtained in 9), the probability density distribution of the Limit State Function G is obtained.

\subsubsection{Results of the Analysis of Target Safety Index and the Acceptable Probability of Failure in Floor Evacuation}

\section{(1) Example of Simulation}

As an example, the result of Monte-Carlo simulation is shown in Figure 45, when a total floor area of the room or $500 \mathrm{~m}^{2}$ and the floor is divided into 3 rooms. 


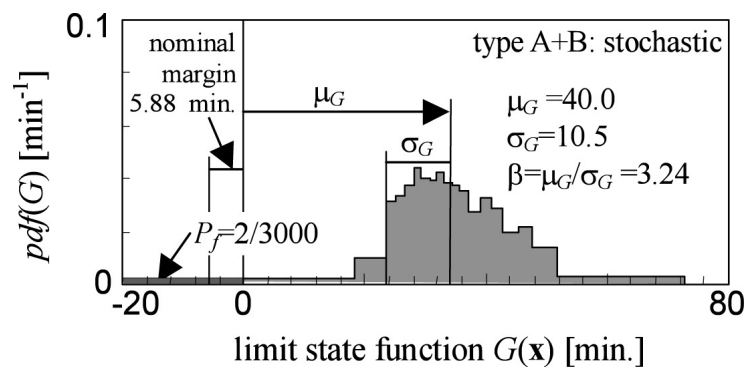

Figure 45 Example of Monte-Carlo Simulation

(Aload $=500$, both rooms and corridor adopt Smoke Filling System), (Aroom, $\max =377 \mathrm{~m}^{2}$, Aroom, $\min =19.9 \mathrm{~m}^{2}$ Aco $=60 \mathrm{~m}^{2}, n s t=2$ )

Floor Egress Time Margin obtained using the prescribed values in the Verification Method is 5.88 minutes. Floor Egress Time Margin obtained by Monte-Carlo Simulation is 45.9 minutes in average, with a standard deviation of 10.5 minutes. Target Safety Index of Limit State Function $G$ is derived as follows:

$$
\beta_{\text {target }}=(45.9-5.88) / 10.5=3.24
$$

Since the value of $G$ became negative only twice in the 3000 trials, Acceptable Probability of Failure is obtained as:

$$
p_{f}=2 / 3000(=0.67 \%)
$$

This is extremely small.

\section{(2) Analysis of safety according to the size of the room and the Smoke Control System}

For each of the 9 combinations of the Smoke Control System of the rooms and the corridor (Smoke Filling System, Natural Ventilation System, and Mechanical Ventilation System), the changes in the Target Safety Index and the Acceptable Probability of Failure was analyzed when the total floor area of the room Aload was varied in the range between 200 and $3000 \mathrm{~m}^{2}$. The weighted average is calculated for the obtained result (the values obtained for each number of rooms on the floor are weighted by the emergence probability of the particular number of rooms on the floor). The results are shown below. We will present only the result for Smoke Filling System, since when Natural Ventilation System or Mechanical Ventilation System are selected as the smoke control system, all the results obtained were almost the same regardless of the Smoke Control System of the corridor [Note 14]. Therefore, the combination of Smoke Control System of the rooms and the corridor presented in Table 7 denoted with "-" have also been analyzed, although the details are omitted in this paper. Also, for these cases, the result is presented according to the number of rooms on the floor since the difference in the number of rooms on the floor will have a large influence on the deviation of the results of the weighted average. 
Table 7 Combination of Smoke Control System of the Fire Room and the Corridor

\begin{tabular}{|c|c||c|c|c|}
\hline \multicolumn{2}{|c||}{} & \multicolumn{3}{c|}{ Corridor } \\
\cline { 3 - 5 } \multicolumn{2}{|c|}{ Smoke Control System } & $\begin{array}{c}\text { Smoke } \\
\text { Filling } \\
\text { System }\end{array}$ & $\begin{array}{c}\text { Natural } \\
\text { Ventilation } \\
\text { System }\end{array}$ & $\begin{array}{c}\text { Mechanical } \\
\text { Ventilation } \\
\text { System }\end{array}$ \\
\hline \hline \multirow{3}{*}{ Rooms } & Smoke Filling System & $1)$ & $1)$ & $1)$ \\
\cline { 2 - 5 } & Natural Ventilation System & $2)$ & - & - \\
\cline { 2 - 5 } & Mechanical Ventilation System & $3)$ & - & - \\
\hline
\end{tabular}

\section{1) The Cases of the Fire Room Adopting Smoke Filling System}

The results of the analysis for the condition where a Smoke Filling System is chosen as the Smoke Control System of the rooms, and Smoke Filling System, Natural Ventilation System, or Mechanical Ventilation System is chosen for the corridor are shown in Figure 46. On each graph, the horizontal axis denotes the total floor area of the room Aload, the left vertical axis denotes the Target Safety Index, and the right vertical axis denotes the Acceptable Probability of Failure.

When a Smoke Filling System is adopted for the corridor, the Target Safety Index falls roughly between 2 and 3 with the exception of the cases where the total floor area of the room is considerably small. A discontinuous change can be seen in the value of Target Safety Index when the total floor area of the room is in the vicinity of $1900 \mathrm{~m}^{2}$. This is a consequence of the discontinuity in the change in the rate of smoke flowing out to the corridor caused by the increase in the number of exits from the rooms at a floor area of $1900 \mathrm{~m}^{2}$. Acceptable Probability of Failure is around $0.3 \%$.

When a Natural Ventilation System or Mechanical Ventilation System is chosen for the corridor, the value of the Target Safety Index will be approximately 3, with the exception of considerably small-scale samples. This is shown in Figure 46 (i) and (ii). Acceptable Probability of Failure is almost zero in the case of Natural Ventilation System, and $0.5 \%$ or less even in the case of Mechanical Ventilation System.

Under the conditions of those analysis, the smoke that enters the corridor will be limited to the small amount that will leak out through the gap of the fire door, hence, the smoke ventilation of the corridor will always be superior. This implies that if a fire door is placed at the openings in between the rooms and the corridor, and a Smoke Control System is installed for the corridor, the safety index will be determined without a remarkable dependence on Egress Start Time and the other design variables. 

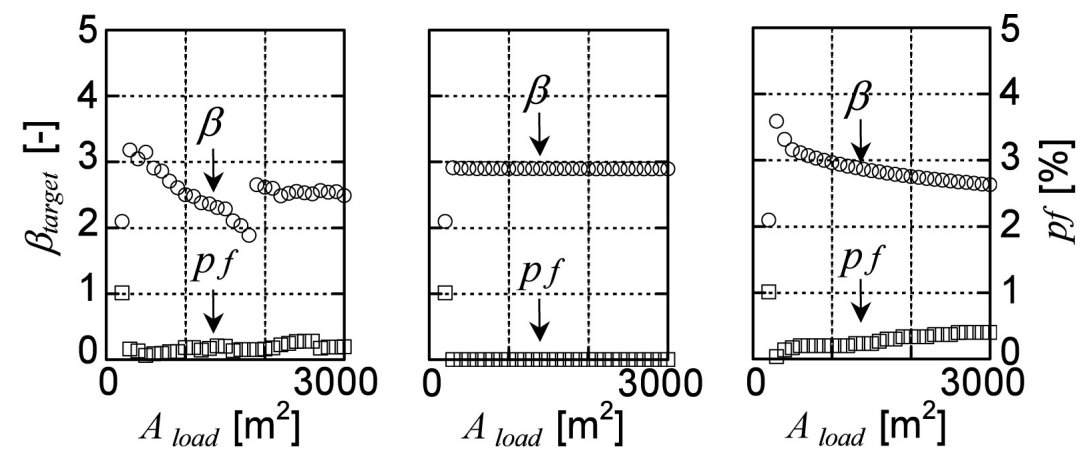

(i) Smoke Filling System (ii) Natural Ventilation System (iii) Mechanical Ventilation System

Figure 46 Target Safety Index and the Acceptable Probability of Failure when the Fire Room adopt Smoke Filling System (by Smoke Control System of the Corridor)

\section{2) The Cases of the Fire Room Adopting Natural Ventilation System and the Corridor Adopting Smoke Filling System}

Target Safety Index and the Acceptable Probability of Failure are shown in Figure 47 for the condition that the rooms adopt a Natural Ventilation System and the corridor adopts a Smoke Filling System. The value of Target Safety Index fell roughly in the range between 1.5 and 3, and Acceptable Probability of Failure was close to zero. There is a discontinuity of the Target Safety Index at the total floor area of the room of $1500 \mathrm{~m}^{2}$. This discontinuity reflects the fact (the analysis condition derived from the results of survey on the existing office buildings) that the frequency used as a single room is high $(77 \%)$ in the case of the floors with areas below $1500 \mathrm{~m}^{2}$, whereas the floors with areas exceeding $1500 \mathrm{~m}^{2}$ are divided into at least 2 rooms. Figure 48 shows the result of the calculation, obtained by fixing the number of rooms on the floor $(1-4)$. The result shows that the Target Safety Index will be largest when the whole floor is used as a single room, and that the value will become smaller when the floor is divided into smaller rooms. Therefore, in the Verification Method the case when the whole floor will be used as single room will require a high level of safety. 


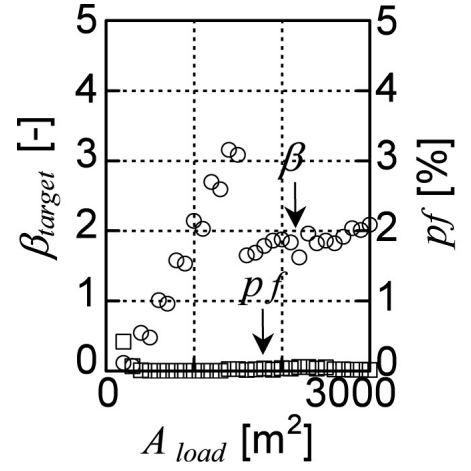

Figure 47 Target Safety Index and the Acceptable Probability of Failure when Natural Ventilation System is installed in the rooms and the corridor adopts Smoke Filling System

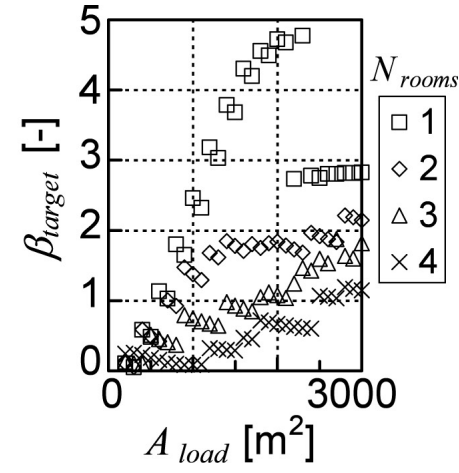

Figure 48 Target Safety Index and the Acceptable Probability of Failure with the Number of Rooms on the Floor $N_{\text {rooms }}$ Fixed at 1 to 4 (under the same condition as Figure 47 for Smoke Ventilation System)

\section{3) The Cases of the Fire Room Adopting a Mechanical Ventilation System}

Figure 49 shows the Target Safety Index and the Acceptable Probability of Failure for the combination of rooms adopting a Mechanical Ventilation System and with a corridor adopting a Smoke Filling System. The values of Target Safety Index are between 2 and 3, which is similar to the case of a Natural Ventilation System. In the case of a Mechanical Ventilation System, a discontinuity is apparent at the total floor area of the room of $1100 \mathrm{~m}^{2}$. Figure 50 shows the result of the calculation, obtained by fixing the numbers of rooms on the floor (1 to 4 ). The result shows a discontinuity when the floor is used as a single room and the floor area is $1100 \mathrm{~m}^{2}$. The discontinuity occurs because the smoke ventilation exceeds the generation of smoke at the floor area of $1100 \mathrm{~m}^{2}$.

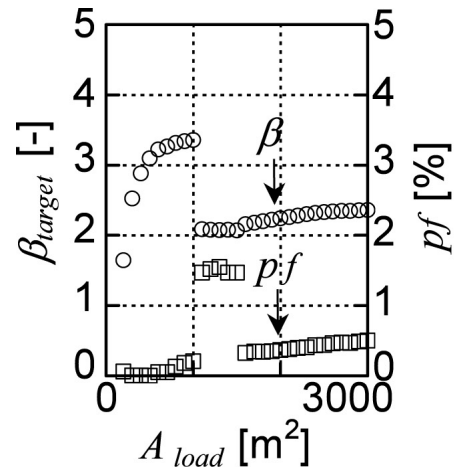

Figure 49 Target Safety Index and the Acceptable Probability of Failure when Mechanical Ventilation System is installed in the rooms, and Smoke Filling System is installed in the corridor

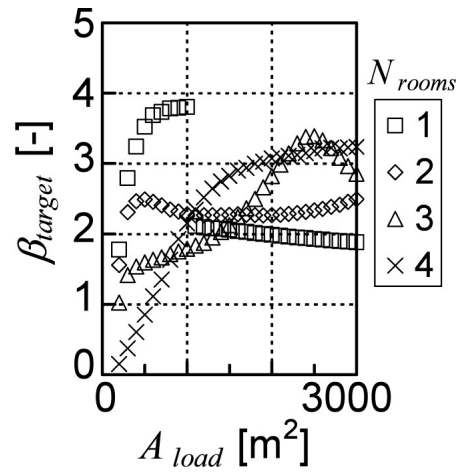

Figure 50 Target Safety Index and the Acceptable Probability of Failure with the Number of Rooms on the Floor $N_{\text {rooms }}$ Fixed at 1 to 4 (under the same condition as Figure 49 for Smoke Ventilation System) 


\subsubsection{Consideration of Sensitivities of the Stochastic Variables and the Most Probable Failure Point in Floor Evacuation}

For the 36 combinations of Smoke Control Systems of the rooms and the corridor

(9 types) and the divisions of the floor $N_{\text {room }}=1$ to 4 , the change in the sensitivity of the Stochastic Variables to the Egress Time Margin is analyzed using the same method (Section 4.1.3) as in the case of room evacuation (Section 4.2.4). When the corridor adopted Smoke Filling System, the tendencies in the changes showed differences between the Smoke Control Systems adopted by the fire room. On the other hand, when the corridor adopted Natural Ventilation System or Mechanical Ventilation System, the tendencies in the changes did not exhibit any differences by the Smoke Control Systems adopted by the fire room. The main characteristics are outlined in the following sections. Simulation is also performed in this Section for each number of rooms on the floor. Finally, when deciding the Partial Safety Factor of the stochastic variables corresponding to the MPFP, the averages are proposed for each of analysis conditions of the building plan; the combinations of the number of rooms on the floor (1 to 4$)$ and the Smoke Control System for the rooms and the corridor (9 types) for the ease of use in the building design practices.

\section{(1) The Cases of the Fire Room Adopting Smoke Filling System}

\section{1) The Cases of the Corridor Adopting Smoke Filling System}

Figure 51 shows the changes in the sensitivity when both fire room and the corridor adopt a Smoke Filling System. Compensating Rate $f_{t s 1}$ of the Smoke Filling Time of the fire room will be the Stochastic Variables giving the maximum Relative Sensitivity when the number of rooms on the floor is between 1 and 3. However, the influence of the Compensating Rate $f_{t s} 2$ of the Smoke Filling Time of the corridor will increase as the number of rooms on the floor becomes larger, and the value will reach its maximum when the number of rooms on the floor is 4 . When the number of rooms on the floor are few, the floor area of the fire room will be considerably larger compared with the floor area of the corridor, which will lead to a longer Smoke Filling Time of the fire room, resulting in a higher sensitivity of its Compensating Rate $f_{t s} 1$. When the number of rooms on the floor increases, floor area of the rooms will become smaller, and the Smoke Filling Time of the corridor will become relatively long, leading to a higher sensitivity of the Compensating Rate $f_{t s}$. Overall, the other Stochastic Variables with large Relative Sensitivities are: Compensating Rate $f \mathrm{a}_{f}$ of the Fire Growth Rate of the Fuel Load, Compensating Rate of Egress Start Time $f_{\text {tstart }}$, and Fuel Load Density $q l$ (in the descending order). Note that Compensating Rate $f_{\text {tstart }}$ of the Egress Start Time tends to become higher in buildings of smaller scale. 


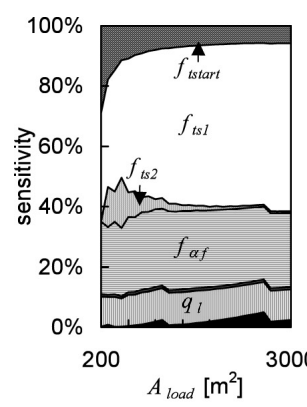

(i) $N_{\text {rooms }}=1$

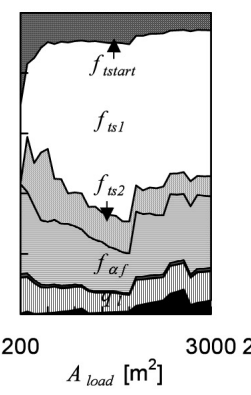

(i i ) $N_{\text {rooms }}=2$

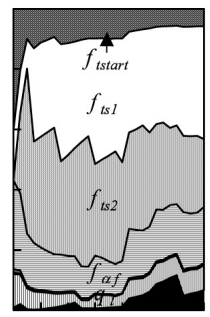

$A_{\text {lood }}\left[\mathrm{m}^{2}\right]$

(i i i ) $N_{\text {rooms }}=3$

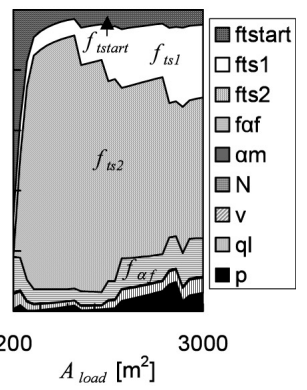

(iv) $N_{\text {rooms }}=4$

Figure 51 Comparison of the Relative Sensitivity of the Stochastic Variables

(Smoke Filling System for both the rooms and the corridor)

Based on the analysis above, Partial Safety Factor corresponding to the MPFP was obtained using the same method (Section 4.1.3) as in Room Evacuation (Section 4.2.4) for the high sensitivity variables. As shown in Figure 52, Partial Safety Factor corresponding to the MPFP was obtained for the Stochastic Variables that presented the 5 highest sensitivities in the analysis above $\left(f_{t s 1}, f_{t s 2}, f \alpha f, f_{t s t a r t}\right.$, and $\left.q l\right)$, and were sorted by the number of rooms on the floor.
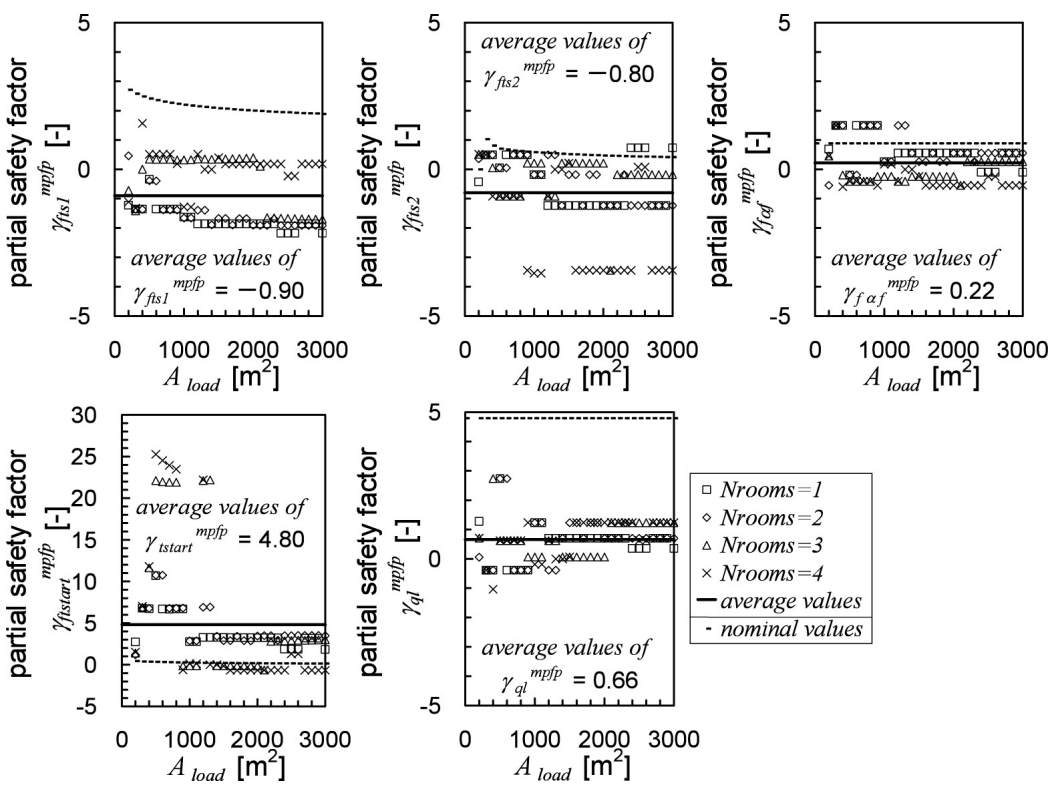

Figure 52 Partial Safety Factor of the Stochastic Variables corresponding to the MPFP (Smoke Filling System for both the rooms and the corridor)

When the number of divisions of the rooms is 3 and 4 compared with the case when the value is 1 and $2, f_{t s} 1$ takes a value slightly over 1 , and the Partial Safety Factor becomes larger. When the number of rooms on the floor is 4, the Partial Safety Factor for $f_{t s 2}$ takes a value smaller than -3, although overall, the value of $f_{t s} 2$ stays within the 
range slightly less then 1 or below. When the scale the building is small and the number of rooms on the floor is 1 or 2 , the Partial Safety Factor for $f \mathrm{a}_{f}$ takes a value around 1.5. In overall, the value will stay under 1 . When the scale of the building is small and the number of rooms on the floor is 3 or 4 , the Partial Safety Factor for $f_{\text {tstart }}$ becomes large. Partial Safety Factor will mostly exceed 6 when the number of rooms on the floor is 1 or 2 , and the value will be around 3 even when the scale of the building is large. The value of the remaining variable $q l$ is mainly found in a range slightly over 1 .

As in the case of $f_{\text {tstart }}$, Partial Safety Factors corresponding to the MPFP may exhibit variations due to the influence of the number of rooms on the floor or the scale of the building. However, in this analysis, we will use the simple average value as being appropriate. The values are presented here for each of the graphs. In comparison with the Partial Safety Factor of the input value prescribed in the Verification Method (nominal values in the figure), the Partial Safety Factor considered as appropriate would be extremely small compared with the prescribed value in the Verification Method for $f_{t s} 2$ and $q_{l}$ (around -0.8 for $f_{t s} 2$ and around 0.7 for $q_{l}$ ), comparatively small for $f_{t s} 1$ and $f$ $\mathrm{a}_{f}$ (around -0.9 for $f_{t s} 1$ and around 0.2 for $f \mathrm{a}_{f}$ ), and on the other hand, extremely large compared with the prescribed value in the Verification Method for $f_{\text {tstart }}$ (around 4.8). Adopting these values as the Partial Safety Factor would enable a configuration close to the MPFP, and therefore would be able to provide the Safety Level roughly equivalent to the level that is provided in the Verification Method.

\section{2) The cases of the Corridor Adopting Natural Ventilation System or Mechanical Ventilation System}

Figure 53 shows the changes in the sensitivity when the rooms adopt a Smoke Filling System and the corridor adopts a Natural Ventilation System. As shown in the figure, the governing factor is the Compensating Rate $f_{t s} 2$ of the Smoke Filling Time for the corridor. This tendency is the same with the case when a Mechanical Ventilation System is adopted for the corridor. Therefore, for both of these variables, the Partial Safety Factor corresponding to the MPFP of $f_{t s} 2$ is shown in Figure 54. The MPFP almost coincides with the mean value when a Natural Ventilation System is adopted for the corridor, and the value of the Partial Safety Factor corresponding to the MPFP will be -3.23 on average when Mechanical Ventilation System is adopted. This implies that the configuration accepts mean value plus around 3 times the value of the standard deviation into the unsafe direction. 


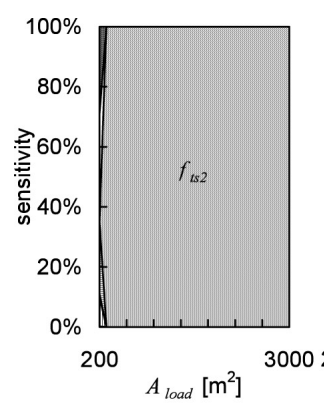

(i) $N_{\text {rooms }}=1$

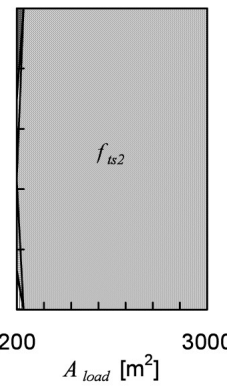

(i i ) $N_{\text {rooms }}=2$

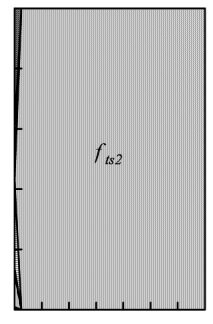

$A_{\text {lood }}\left[\mathrm{m}^{2}\right]$

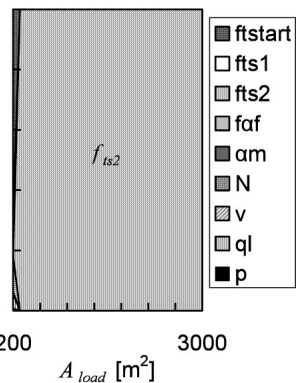

(iv) $N_{\text {rooms }}=4$

Figure 53 Comparison of the Relative Sensitivity of the Stochastic Variables (Smoke Filling System for the rooms, Natural Ventilation System for the corridor)

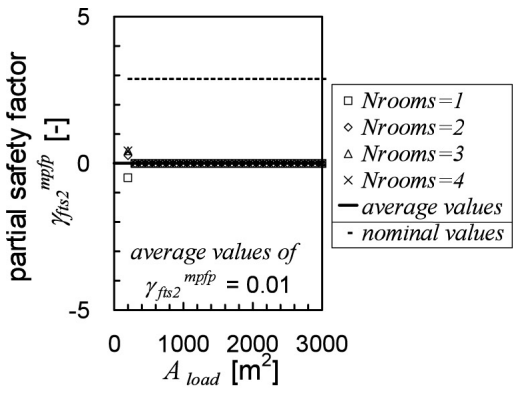

(1) Rooms - Smoke Filling System,

Corridor - Natural Ventilation System

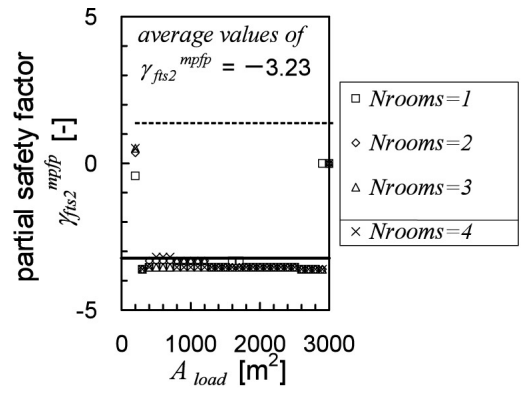

(2) Rooms - Smoke Filling System,

Corridor - Mechanical Ventilation System

Figure 54 Partial Safety Factor of the Stochastic Variables corresponding to the MPFP (Rooms - Smoke Filling System, Corridor - Ventilated)

\section{(2) The cases of the Fire Room Adopting Natural Ventilation System}

Figure 55 shows the changes in the sensitivity when the rooms adopt a Natural Ventilation System and the corridor adopts a Smoke Filling System. When the floor is divided into 1 or 2 rooms, the overall tendency of the order of the Relative Sensitivity is (in descending order): Compensating Rate for the Smoke Filling Time for the rooms $f_{t s}$; Compensating Rate for the Fire Growth Rate of the Fuel Load $f a f$; and Fuel Load Density ql. The Stochastic Variables concerning smoke generation and behavior in the fire rooms show high sensitivities. When the floor is divided into 3 or 4 rooms, the sensitivity of $f_{t s} 1$ becomes small, the sensitivity of the Fire Growth Rate of the interior finishing material $a_{m}$ becomes high, and overall, the sensitivity of the Stochastic Variable concerning smoke generation in the fire room becomes the governing factor. There is a same tendency in the cases adopting a Natural Ventilation System or Mechanical Ventilation System for the corridor, and the Compensating Rate of the Smoke Filling Time $f_{t s} 2$ showed a tendency of high sensitivity in smaller-scale buildings. 
Figure 56 shows the Partial Safety Factor corresponding to the MPFP of the 4 Stochastic Variables with high sensitivity $\left(f_{t s} 1, f \alpha_{f}, q l, \alpha_{m}\right)$. Overall, the Partial Safety Factor corresponding to the MPFP is close to zero, i.e. the MPFP almost coincides with the simple average value, however, the Partial Safety Factors show some variation when the floor is used as a single room. A value considered as appropriate is calculated and given in the graph as a mean value. The diagrams showing the results for the cases where the corridor adopts a Natural Ventilation System or Mechanical Ventilation System are omitted, and the results of Partial Safety Factor corresponding to the MPFP concerning the Stochastic Variables with high sensitivity are presented later in the Table 8.

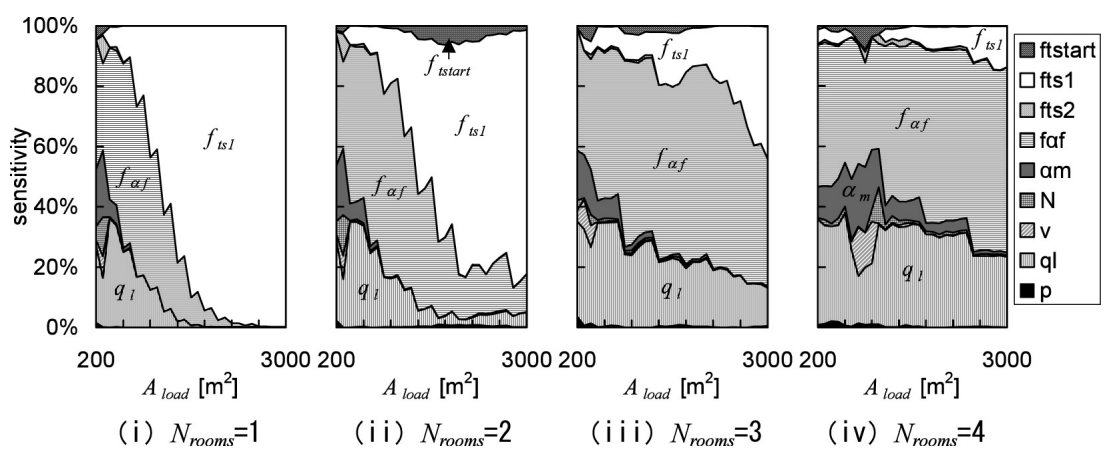

Figure 55 Comparison of the Relative Sensitivity of the Stochastic Variables (rooms - Natural Ventilation System, corridor - Smoke Filling System)
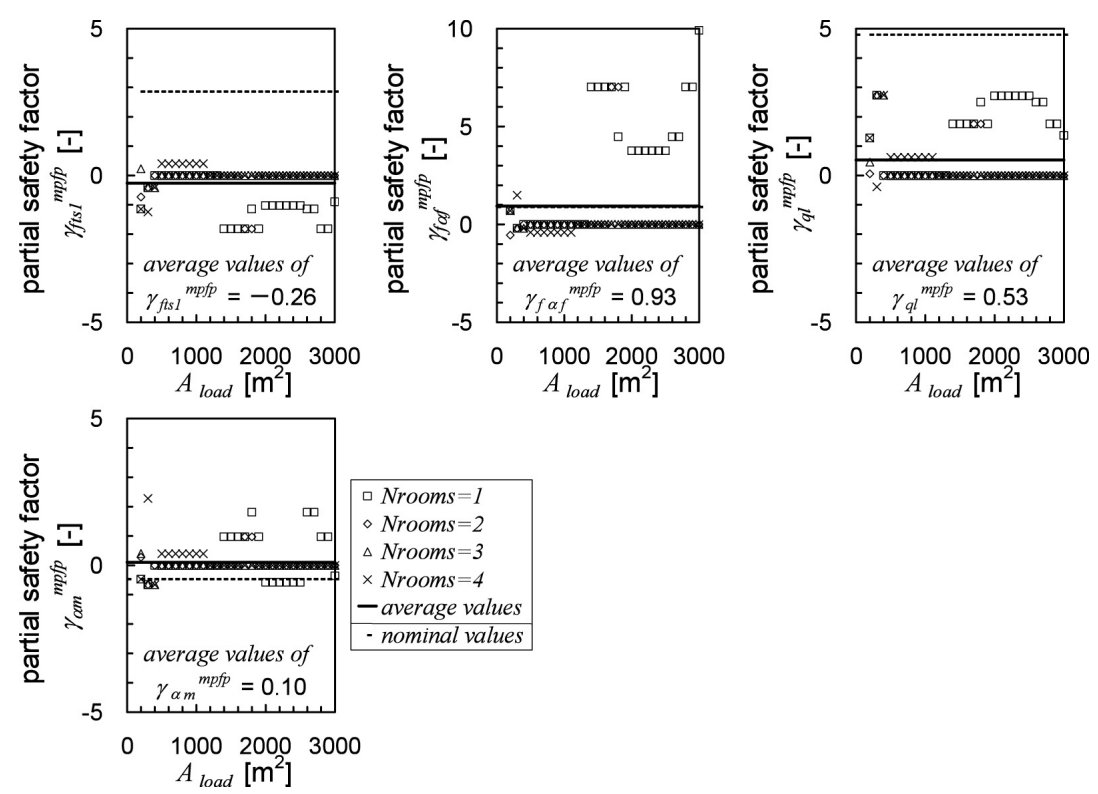

Figure 56 Partial Safety Factor of the Stochastic Variables corresponding to the MPFP (rooms - Natural Ventilation System, corridor - Smoke Filling System) 


\section{(3) The Cases of the Fire Room Adopting Mechanical Ventilation System}

Figure 57 shows the changes in the sensitivity when the rooms adopt a Mechanical Ventilation System and the corridor adopts Smoke Filling System.

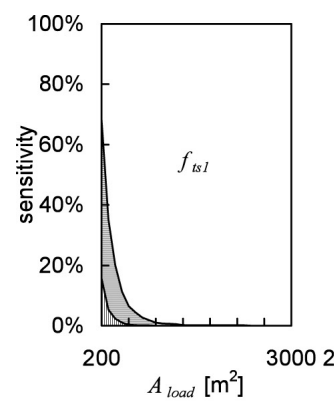

(i) $N_{\text {rooms }}=1$

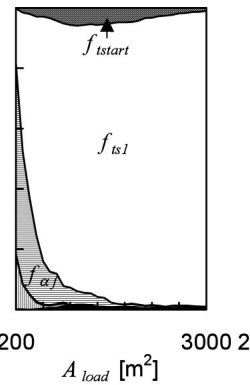

(i i ) $N_{\text {rooms }}=2$

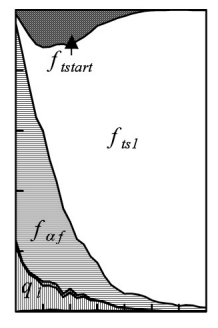

$A_{\text {load }}\left[\mathrm{m}^{2}\right]$

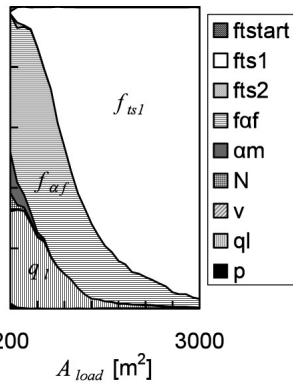

(iv) $N_{\text {rooms }}=4$

Figure 57 Comparison of the Relative Sensitivity of the Stochastic Variables (rooms - Mechanical Ventilation System, corridor - Smoke Filling System)

There is an overall tendency that the influence of $f_{t s 1}$ becomes larger compared with the cases when the rooms adopt a Natural Ventilation System. Therefore, the overall tendency of the order of the Relative Sensitivity is (in descending order): Compensating Rate for the Smoke Filling Time for the rooms $f_{t s}$, Compensating Rate for the Fire Growth Rate of the Fuel Load $f a f$, and Fuel Load Density ql. Compensating Rate of Egress Start Time $f_{\text {tstart }}$ shows a higher sensitivity when the scale of the building is small and the floor is divided into 2 or 3 rooms. The same tendency could be seen in corridors adopting a Natural Ventilation System and a Mechanical Ventilation System.

Figure 58 shows the Partial Safety Factor corresponding to the MPFP of the 4 Stochastic Variables with high sensitivity $\left(f_{t s 1}, f \mathrm{a}_{f}, q l, f_{\text {tstart }}\right)$. Overall, the Partial Safety Factor of the MPFP shows a tendency to take a value close to zero. When the floor is divided into 1 or 3 rooms, there are some cases where the Partial Safety Factor becomes small for $f_{t s 1}$, large for $q l$, and extremely large for $f \mathrm{a}_{f}$. A value considered as appropriate is calculated and given in the graph as a mean value. The diagrams showing the results for the cases where the corridor adopts a Natural Ventilation System or Mechanical Ventilation System are omitted, as we have done in the case of a Natural Ventilation System. 

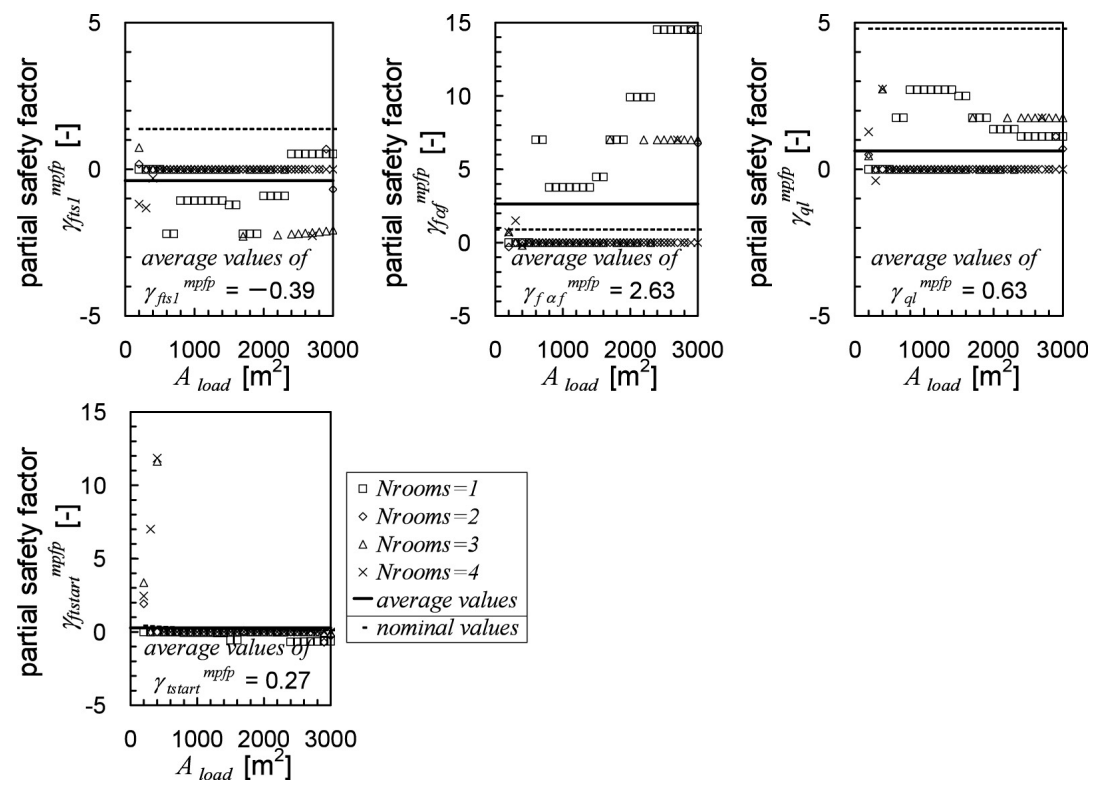

Figure 58 Partial Safety Factor of the Stochastic Variables corresponding to the MPFP (Rooms - Mechanical Ventilation System, Corridor - Smoke Filling System)

\section{(4) Partial Safety Factor Corresponding to the Most Probable Failure Point}

In the subsections (1) - (3) above, the Partial Safety Factor of the Stochastic Variables with high sensitivity has been presented corresponding to the MPFP obtained for several combinations of Smoke Control System of the rooms and the corridor, and the number of rooms on the floor. Since several of the combinations have been omitted in these subsections, the results corresponding to all combinations of Smoke Control System for the rooms and the corridor, and the number of rooms on the floor, are shown in Table 8 . The difference due to the Smoke Control System is not as significant as in the case of room evacuation. The same level of safety as in the Verification Method can be maintained if the variables are configured as follows [Note 15]: around 0.7 for $q l$, around 2.6 for $f \mathrm{a}_{f}$, around 4.8 for $f_{\text {tstart }}$, around 0 for $\alpha_{m}$, and around 0 for $f_{t s}$ (for both the rooms and the corridors). 
Table 8 Partial Safety Factor for MPFP

\begin{tabular}{|c|c|c|c|c|}
\hline \multicolumn{2}{|c|}{$q l$} & \multicolumn{3}{c|}{ Corridor } \\
\hline \multicolumn{2}{|c|}{4.97} & $\mathrm{~S}$ & $\mathrm{~N}$ & $\mathrm{M}$ \\
\hline \multirow{3}{*}{ Rooms } & $\mathrm{F}$ & 0.66 & - & - \\
\cline { 2 - 5 } & $\mathrm{N}$ & 0.53 & 0.03 & -0.05 \\
\cline { 2 - 5 } & $\mathrm{M}$ & 0.63 & 0.02 & 0.01 \\
\hline
\end{tabular}

\begin{tabular}{|c|c|c|c|c|}
\hline \multicolumn{2}{|c|}{$f_{\text {tstart }}$} & \multicolumn{3}{c|}{ Corridor } \\
\hline \multicolumn{2}{|c|}{-0.38} & $\mathrm{~S}$ & $\mathrm{~N}$ & $\mathrm{M}$ \\
\hline \multirow{3}{*}{ Rooms } & $\mathrm{F}$ & 4.80 & - & - \\
\cline { 2 - 5 } & $\mathrm{N}$ & - & - & - \\
\cline { 2 - 5 } & $\mathrm{M}$ & 0.27 & - & - \\
\hline
\end{tabular}

\begin{tabular}{|r|c|c|c|c|}
\hline \multicolumn{2}{|c|}{$f_{a f}$} & \multicolumn{3}{c|}{ Corridor } \\
\hline \multirow{2}{*}{1.07} & $\mathrm{~S}$ & $\mathrm{~N}$ & $\mathrm{M}$ \\
\hline \multirow{3}{*}{ Rooms } & $\mathrm{F}$ & 0.22 & - & - \\
\cline { 2 - 5 } & $\mathrm{N}$ & 0.93 & 0.01 & -0.06 \\
\cline { 2 - 5 } & $\mathrm{M}$ & 2.63 & 0.01 & 0.02 \\
\hline
\end{tabular}

\begin{tabular}{|c|c|c|c|c|}
\hline \multicolumn{2}{|c|}{$\alpha_{m}$} & \multicolumn{3}{c|}{ Corridor } \\
\hline \multicolumn{2}{|c|}{-0.46} & $\mathrm{~S}$ & $\mathrm{~N}$ & $\mathrm{M}$ \\
\hline \multirow{3}{*}{ Rooms } & $\mathrm{F}$ & - & - & - \\
\cline { 2 - 5 } & $\mathrm{N}$ & 0.10 & 0.00 & 0.00 \\
\cline { 2 - 5 } & $\mathrm{M}$ & - & - & - \\
\hline
\end{tabular}

\begin{tabular}{|c|c|c|c|c|}
\hline \multicolumn{2}{|c|}{$f_{t s l}$} & \multicolumn{3}{c|}{ Corridor } \\
\hline \multicolumn{2}{|c|}{$*$} & $\mathrm{~S}$ & $\mathrm{~N}$ & $\mathrm{M}$ \\
\hline \multirow{3}{*}{ Rooms } & $\mathrm{F}$ & -0.90 & - & - \\
\cline { 2 - 5 } & $\mathrm{N}$ & -0.26 & -0.02 & -0.52 \\
\cline { 2 - 5 } & $\mathrm{M}$ & -0.39 & 0.00 & 0.00 \\
\hline
\end{tabular}

\begin{tabular}{|c|c|c|c|c|}
\hline \multicolumn{2}{|c|}{$f_{t s 2}$} & \multicolumn{3}{c|}{ Corridor } \\
\hline \multirow{2}{*}{$* *$} & $\mathrm{~S}$ & $\mathrm{~N}$ & $\mathrm{M}$ \\
\hline \multirow{3}{*}{ Rooms } & $\mathrm{F}$ & -0.80 & 0.01 & -3.23 \\
\cline { 2 - 5 } & $\mathrm{N}$ & - & 0.00 & -1.61 \\
\cline { 2 - 5 } & $\mathrm{M}$ & - & - & - \\
\hline
\end{tabular}

[Table notation]

The stochastic Variables are shown in the upper left of the table, and the Partial Safety Factor of the prescribed values in the Verification Method are shown below the Stochastic Variables. Also, the Partial Safety Factor corresponding to the Most Probable Failure Point are distinguished by the smoke control systems for the room and the corridor (expressed as follow, F: Smoke Filling System, N: Natural Ventilation System and M: Machinery Ventilation System).

*) Partial Safety Factors of the prescribed values in the Verification Method of $f_{t_{S}}$ are; Smoke Filling System: 2.23 (when Aroom $\left.=500 \mathrm{~m}^{2}\right)$; Natural Ventilation System; 2.87, Mechanical Ventilation System: 1.37.

**) Partial Safety Factors of the prescribed values in the Verification Method of $f_{t_{S} 2}$ are; Smoke Filling System: $3.25\left(\right.$ when $\left.A_{c o}=100 \mathrm{~m}^{2}\right)$; Natural Ventilation System and Mechanical Ventilation System: same values as for $f_{t_{s}}$.

\section{CONCLUSION}

In this study the calculation system of the "Verification Method for Egress Safety from a Fire Floor" was evaluated using the method of Reliability Engineering. The uncertainty of the variable recognized as Type A variable (probability variable) and Type B variable (uncertainty of estimation) are quantified, and presented in terms of the Probability Density Function $(p d f)$. In the analysis, the following characteristics became apparent. Note here, that for those variables that require prescribed values of the Verification Method to be configured according the usage of the room, the room was considered to be used for office use. 
(1) Two variables are recognized as Type A variables: Fuel Load Density and Occupant Density. Six variables are recognized as Type B variables: Walking Velocity, Flow Rate, Egress Start Time from the fire room, Fire Growth Rate of the Fuel Load, and Fire Growth Rate of the interior finishing material, and Smoke Filling Time.

(2) The variation coefficients were large (between 13\% and 235\%) for both Type A and Type B variables. The refinement of prediction formulae, especially for Type B variables, is awaited to match the accumulation of study results in order to achieve smaller variation coefficients. There are four variables that are applicable: Smoke Filling Time, Fire Growth Rate of the Fuel Load, Fire Growth Rate of the interior finishing material, and Egress Start Time.

(3) In the current configuration, no relation could be found between the Partial Safety Factor (in the range between -0.45 and 4.97 ) and the variation coefficient.

Next, concerning evacuation from the fire room (room evacuation) or evacuation from the floor including the fire room (floor evacuation), the egress safety requested for a standard floor plan of a typical office building with single side corridor in the "Verification Method for Egress Safety from a Fire Floor" was analyzed using the method of Reliability Engineering. In the analysis, the egress safety performance of the building plan conforming the Verification Method was obtained as an approximate solution, the changes in Target Safety Index and the Acceptable Probability of Failure according to the changes in the value of the floor area (which symbolizes the scale of the design), or the differences in the Smoke Control System installed in the rooms and the corridors were analyzed. Also, issues such as the degree of influence (sensitivity) that the variation of an input variables recognized as a Stochastic Variable will impose on the variation of the Egress Time Margin have been evaluated, as well as the Most Probable Failure Point (MPFP). In order to create a calculation system with a good balance (on average) of elements comprising the Verification Method (the Safety Ratios of the Characteristic Input Values and the prediction formulae), proposals are made for the Partial Safety Factors concerning the prescribed values for the Stochastic Variables with high sensitivity so that the solution will move as close to the MPFP as possible. The following conclusions were obtained from the results of the analysis above [Note 16].

Concerning room evacuation:

(4) Target Safety Index shows a certain dependency on the type of Smoke Control System and the area of the room, however, overall the value falls within the range of 1 to 3. The corresponding Acceptable Probability of Failure will be 5 to $10 \%$.

(5) The influence of the uncertainty of Type B variables (estimation error of the calculation equation) is large compared with the variation of Type A variables (the original variable components such as Fuel Load Density and Occupant Density).

(6) MPFP and Design Point will coincide well, providing a well-balanced calculation system, when Partial Safety Factor for each variable will take the following values: around 0.7 for Fuel Load Density, 2 to 8 for Egress Start Time, and around 0.9 for Smoke Filling Time. Concerning floor evacuation: 
(7) Target Safety Index shows a certain dependency on the type of Smoke Control System and the area of the room, however, overall the value falls within the range of 2 to 3. The corresponding Acceptable Probability of Failure will be $0.5 \%$ or less.

(8) MPFP and Design Point will coincide well, providing a well-balanced calculation system, when Partial Safety Factor for each variable will take the following values: around 0.7 for Fuel Load Density, around 4.8 for Egress Start Time, around 2.6 for Fire Growth Rate of fuel load, and around 0 for Smoke Filling Time.

Compared to (4) or (7) mentioned above, the egress safety from the floor including the fire room requires a somewhat higher Level of Safety. In adopting the contents of (6) and (8), the Egress Start Time and the Fire Growth Rate of the Fuel Load must be configured largely towards the safer side compared with the currently prescribed values in the Verification Method. As described in (2) above, these prediction formulae provide results with low estimation precision. This is partly due to the fact that the value of Egress Start Time replaced the actual measurement with a calculation using models close to reality, and that the number of samples of Fire Growth Rate of the Fuel Load were few. It also implies that the verification of the prediction formulae by actual research and experimentation is not sufficient, and that measures such as improvement of estimation models are required for a further accuracy improvement.

\title{
ACKNOWLEDGMENT
}

The authors would like to thank Mr. M. Shimamura (Formerly Graduate student, Tokyo Univ. of Science) for fully support of this survey on the existing office building plan and this Monte-Carlo simulation. The work is supported (in part) by grant-aided project of Japan Ministry of Education, Culture, Sports, Science and Technology (the 21st Century COE Program "Center of Advanced Fire Safety Science and Technology for Building", TUS).

\section{NOMENCLATURE}

\author{
$<$ Roman Letters $>$ \\ a Regression Sensitivity Coefficient \\ A area $\quad$ Floor Area Subject to the Calculation of Floor Evacuation $\left[\mathrm{m}^{2}\right]$ \\ $A_{\text {co }} \quad$ Floor Area of the Corridor $\left[\mathrm{m}^{2}\right]$ \\ Aload Total Floor Area of the Rooms Sharing a Particular Egress Route $\left[\mathrm{m}^{2}\right]$ \\ Aroom Floor Area of the Room $\left[\mathrm{m}^{2}\right]$ \\ Aroom,max $\quad$ Maximum Floor Area of the Rooms $\left[\mathrm{m}^{2}\right]$ \\ Aroom,min Minimum Floor Area of the Rooms $\left[\mathrm{m}^{2}\right]$ \\ $A_{\text {St }} \quad$ Floor Area of the Escape Staircase $\left[\mathrm{m}^{2}\right]$ \\ $A_{w} \quad$ Area of Interior Finishing Material in Contact with the Flame $\left[\mathrm{m}^{2}\right]$
}




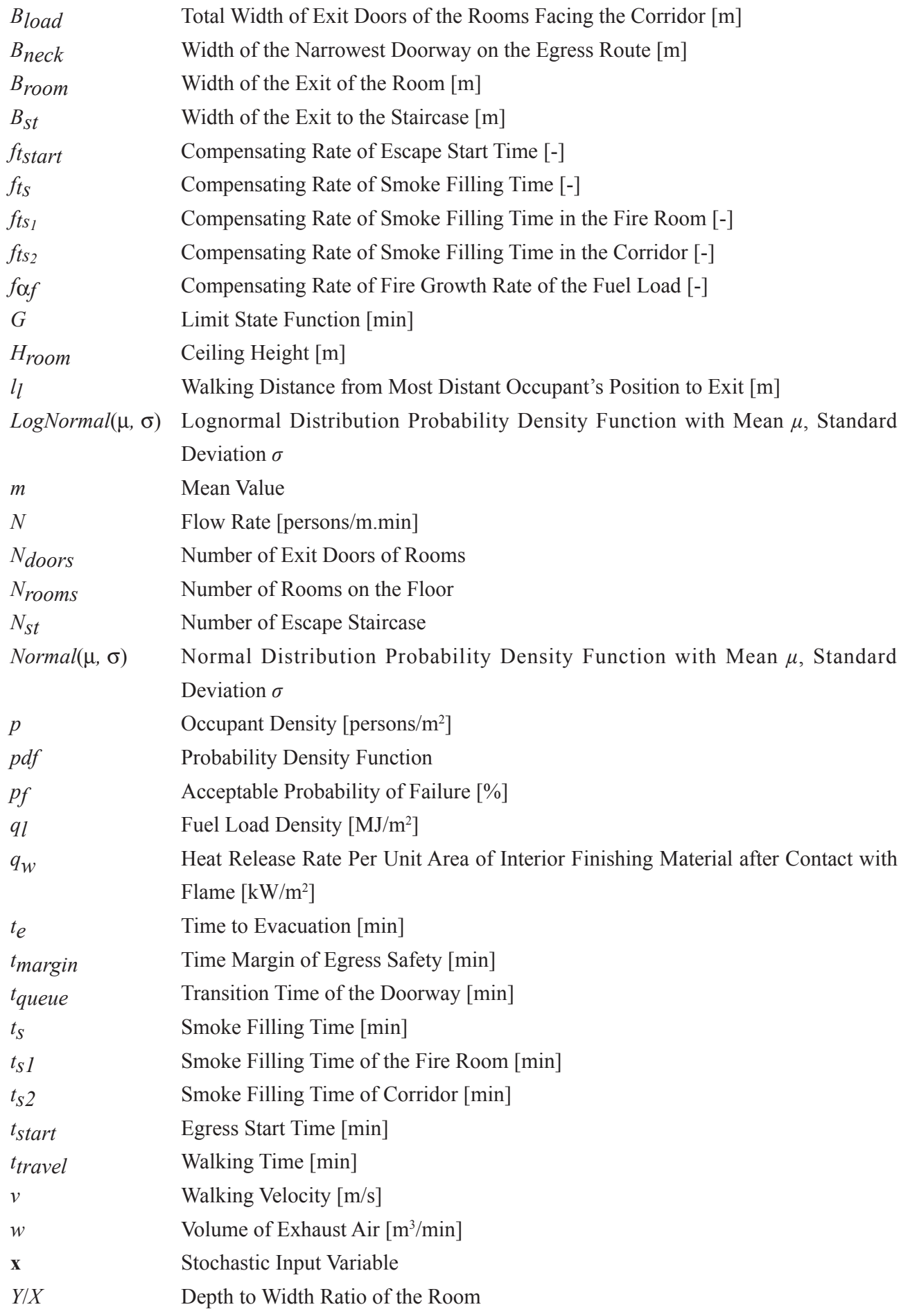




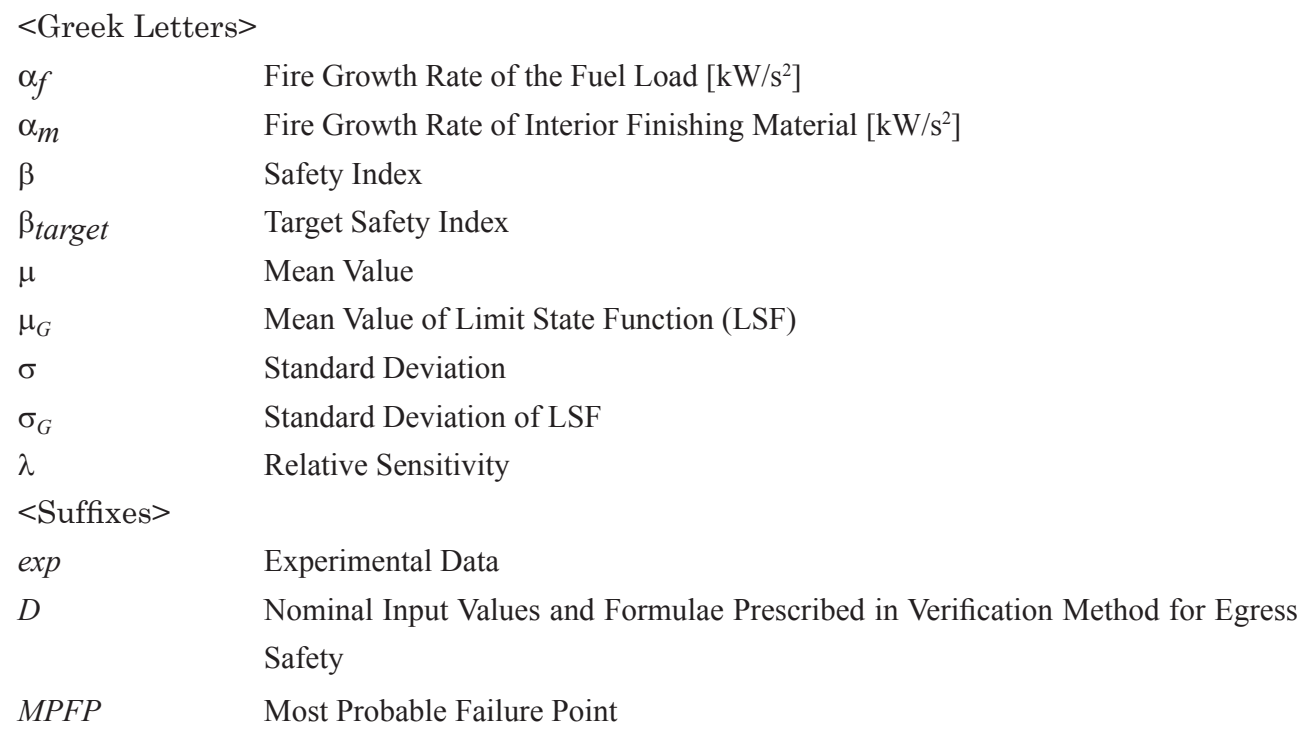

\section{NOTES}

[1] In the framework of the Building Standard Law of Japan, to provide the actuation reliability of various pieces fire-prevention equipment, the Verification Method is applied under the assumption that the actuation reliability is guaranteed by the technical standards of each piece of equipment. In the analysis performed in this study, it is considered that the actuation reliability of each piece of equipment is provided with other means and is not dealt with in the scope of this study.

[2] The results obtained in Reference 6 included a sample of a bank office, which showed an extremely small density compared with other fields of business. It is speculated that the area of the customer lobby was included in the calculation, therefore this sample was excluded from this analysis.

[3] Not enough data was accumulated to perform a quantitative analysis of the time from the recognition of the fire to the decision to evacuate. Here, since 3 minutes added to the square root of the target floor area multiplied by 2 is adopted as the Egress Start Time in the Verification Method for Egress Safety from a Fire Floor, the mean value and the standard deviation are estimated at 1 and 2 minutes respectively, and hence the value is determined as LogNormal $(1,2)^{46}$. 47). Since the time until the risk from the fire becomes prevalent has already been considered, therefore, as described in this paper, the mean value of 1 minute has been subtracted, to provide only the value of uncertainty.

[4] Assuming from the results of the experiments, etc., the combustion rate per floor area of a normal solid fuel load may be considered to be around $0.1 \mathrm{~kg} / \mathrm{s} / \mathrm{m}^{2}$ in many cases. In this paper, the value is multiplied by the calorific value per unit weight of wooden materimals to provide $1600 \mathrm{~kW} / \mathrm{m}^{2}$. 
[5] Normally Equation (17) is applied to a growing fire source (the HRR expressed as $\left.Q=\left(\alpha_{f}+\alpha_{m}\right) t^{2}\right)$, however, many of the existing experiments use a fire source of steady combustion. In the process of deriving Equation (17), heat release of the HRR of constant fire source where the total volume of smoke generation becomes equal is derived as $Q_{\mathrm{a}}=21 \mathrm{\alpha} A_{\text {room }}$, and the smoke filling time corresponding to a constant fire source (HRR $Q_{\alpha}$ ) is derived ${ }^{1)}$. Therefore, to determine $f_{t s}$ from experimental data, HRR obtained experimentally was substituted as $Q_{\alpha}$ in its original state.

[6] The positive direction of the Partial Safety Factor is determined such that the Non-Exceedance of the variable $x$ will increase. Therefore, the positive direction is taken so that the Egress Time Margin $t_{\text {margin }}$ will decrease as $x$ increases.

[7] The method of quantifying the Safety Level requested in the Verification Method (see Figure 22 in this paper) by studying the characteristics of the Limit State Function (Equation (23)) defined here will only hold approximately, however, in the actual cases (when $B$ does not become extremely large), the error can be considered as negligible.

[8] The office buildings that were studied in this paper are as follows (the names are those that are used in the references): Hiroshima MID Building, Crystal Tower, Marubeni Osaka Head Office Building, Osaka Tokyo Marine Head Office Building, Noevir Ginza Building, Enix Head Office Building, Mito Shinkin Bank Head Office, SMBC Leasing Head Office Building, Nakano Vinegar Group Head Office Building, Tokyo Gas Earth Port Building, Humanix Shibuya Building, Kita-aoyama Yoshikawa Building, Sannomiya Dai-ichi Seimei Building, Passage Garden Shibuya Toushi Ikusei Building, Sega Enterprises Head Office Building \#1.

[9] As shown in Table 4, when a Natural Ventilation System is adopted, the area of air intake is assumed to be $(0.9 \times 2.0) \mathrm{m}^{2}$. Therefore, as the area of the smoke ventilation increases with the floor area, the influence of the air-intake on the effective smoke ventilation rate will diminish when the floor area exceeds $400 \mathrm{~m}^{2}$, thus, the balance of smoke ventilation and air intake in this region will be determined solely by the smoke ventilation. Because such a model is used in the formulation of the Verification Method, the trend of increase/decrease of the Target Safety Index will change with the increase/decrease of the floor area.

[10] The surveyed office buildings are the 15 cases (17 standard floors) used in analyzing for room evacuation plus the following 11 cases: [Tokyo Obayashi Building, Daini Maruzen Building, Yasuda Seimei Head Office Building, Aoyama Tower Building, Nagai International Building, Sumitomo Seimei Oita Building, private houses with stores on the Ground floor in the urban area of Nishiokubo City, Shin-Hankyu Building (Osaka), Tenjin Building (Fukuoka), Dai-ichi Seimei Building(Osaka), W Building] (The names are those that are used in the references.)

[11] It must be said that 28 cases is not sufficient for sampling, however, with regards to the standards of the floor area of a fire compartment, it is fair to say that the overall tendency is correctly expressed. 
[12] The number of staircases itself is not a good match with the collected data. This is because the matching of the total width of the exits was the first priority. For your reference, by directly calculating the relation between the total floor area of the escape staircase and the total floor area of the rooms, a value of $A_{S t} / A_{\text {oad }}=2.16$ Aload $^{-0.60}$ is derived as shown in the figure below:

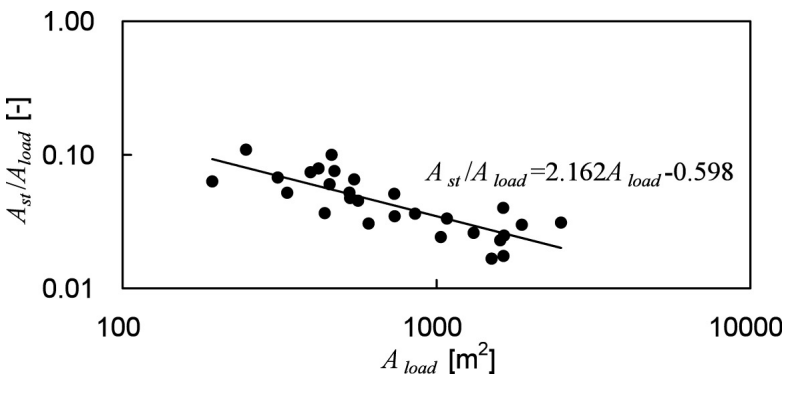

Reference Figure Area of the Escape Staircase

[13] A fire door without the performance of protection against smoke leakage corresponds to a fire door with a structure conforming to Subparagraph 1 of the Article 112, Paragraph 14 of Enforcement Order of Building Standard Law of Japan.

[14] This is because, under the conditions adopted in this simulation, the flow of smoke into the corridor will be extremely small in the case where the rooms adopts a Natural Ventilation System or Mechanical Ventilation System.

[15] The results obtained here consider a standard floor in a typical office building with a single side corridor. For more generality, it would be necessary to consider and analyze other placements of corridors and usages of rooms in the future.

[16] The results obtained here consider a standard floor of a typical office building with a single side corridor. For more generality, it would be necessary to consider and analyze other placements of corridors and usages of rooms in the future. The typical office buildings that will be designed after the implementation of the Verification Method may be more or less different from the samples collected for this study. Therefore, these would provide subjects for future study.

\section{REFERENCES}

1. Ministry of Construction Notification No.1441, 2000: Establishment of Calculation Method Corresponding to Verification Method of Egress Safety from a Fire Floor (Edited by Ministry of Land, Infrastructure and Transport, Housing Bureau, Building Guidance Division, Ministry of Land, Infrastructure and Transport, Building Research Institute, Japan Conference of Building Officials, and The Building Center of Japan: 2001 Edition, Introduction to the Verification Method for Egress Safety, Calculation Examples and Commentary, Inoueshoin, 2001) (in Japanese) 
2. Edited by Architectural Institute of Japan: A Guide and Introduction to Critical State Design of Steel Structures, 1998 (in Japanese)

3. Sven-Erik Magnusson, Häkan Frantzich and Kazunori Harada, "Fire Safety Design Based on Calculations: Uncertainty Analysis and Safety Verification", Fire Safety Journal, Vol. 27, pp.305-334, 1997

4. Magdalena Angerd, Häkan Frantzich, "The Use of Uncertainty Analysis in Performance Based Design", Proceedings of the $4^{\text {th }}$ International Conference on Performance-Based Codes and Fire Safety Design Methods, pp.179-189, Melbourne, Australia, 2002

5. Alfredo Hua-Sing Ang, Wilson H. Tang, Probability Concepts in Engineering Planning and Design, Wiley (New York), 1975

6. Mitsumasa Okada, Katsuyuki Yoshida, Shiro Kashihara, Masanori Tsuji, et al.: Human Engineering for Buildings and Cities, Chapter 4, Mechanism of Space and Behavior, Kajima Institute Publishing, pp249-251, 1977 (in Japanese)

7. Yasuhiko Nagakura, Hiroshi Hara, and Makoto Ishige: Few Considerations on the Number of Occupants in an Office Building, Journal of The Architectural Institute of Japan, No.121, pp.47-53, 1966 (in Japanese)

8. Edited by Japan Association for Fire Science and Engineering: Research on the Probable Number of Occupants in Various Types of Buildings, pp.33-58, 1992 (in Japanese)

9. Edited by The Building Center of Japan: New Guide to Building Fire Protection Plan, 1985 Edition, pp.42-43, 1985 (in Japanese)

10. Edited by MANU Institute for Urban Design and Architecture: Field Study on Fuel Load in Buildings, 1983 (in Japanese)

11. Kenji Aburano, Hidetoshi Yamanaka, Yoshifumi Omiya, Kiyoshi Takahashi, Takeyoshi Tanaka, and Takao Wakamatsu: Analysis of Fuel Load and its Surface Area Based on the Field Study, Journal of Architecture, Planning and Environmental Engineering, The Architectural Institute of Japan, No.483, pp.1-8, 1996 (in Japanese)

12. Edited by The Architectural Institute of Japan, Structure Committee, and Sub-Committee on Limit State Design Method: A Guide to Limit State Design of Buildings (Proposal), 1st Edition, 1999 (in Japanese)

13. J.J.Fruin: Pedestrian Planning and Design, Chapter 3, Kajima Institute Publishing, 1974 (in Japanese)

14. Noriaki Koseki: Bulletin of Railway Technical Research Institute, Railway Technical Research Institute, 1968 (in Japanese)

15. Mitsumasa Okada, Katsuyuki Yoshida, Shiro Kashihara, and Masanori Tsuji: Human Engineering for Buildings and Cities, Chapter 1, Kajima Institute Publishing, 1977 (in Japanese)

16. Toru Uetake, Manabu Watanabe, and Matsunori Nara: Flow Rate of a Crowd in 
Doorways and at the Head of a Staircases, Journal of Japan Association for Fire Science and Engineering, Vol.44, No.1-2, 1996 (in Japanese)

17. Takeyoshi Tanaka: An Introduction to Fire Safety Engineering, The Building Center of Japan, Chapter 8, 1993 (in Japanese)

18. Edited by Fire Prevention Council, Safety Measures for Human Lives Division: Report on Fire Experiment at Mitsubishi Bank, Kanasugibashi Branch, 1974 (in Japanese)

19. Edited by Tokyo Fire Department: Chiyoda Life Experiment, Tokyo Fire Department, 1974 (in Japanese)

20. Edited by Tokyo Fire Department Fire Prevention Council: Fukoku Life Experiment, Tokyo Fire Department, 1976 (in Japanese)

21. Edited by Tokyo Fire Department: Report on Fire Experiment at Kuramae Kokugikan, Tokyo Fire Department, 1985 (in Japanese)

22. Edited by Japanese Society of Steel Construction, Special Committee on Fire Resistance of Steel-Frames: Fire Experiment of Full Size Steel Structure Building, Japanese Society of Steel Construction, 1969 (in Japanese)

23. Edited by Kobe City Fire Bureau: Report on Fire Experiment of Buildings, and so forth, Kobe City Fire Bureau, 1969 (in Japanese)

24. A British Steel Technical, Fire Research Station Collaborative Project: Natural Fires on Large Scale Compartments, Department of Environment Building Research Establishment Fire Research Station, 1992

25. A European Joint Research Programme: The Behaviour of Multi-storey Steel Framed Buildings in Fire, 1999

26. Yoshikazu Uchida: Report on Fire Experiment of Reinforced-concrete Apartment Buildings, (1) Fire Experiment of Reinforced-concrete Apartment Buildings, Journal of Architecture and Building Science, April 1918 (in Japanese)

27. McCaffrey,B.,J., Quintiere, J., G., Harklwroad, M., F., "Estimating Room Temperatures and Likelihood of Flashover Using Fire Test Data Correlations", Fire Technology, 17(2), pp. 98-119, 1981

28. Edited by Ministry of Construction, Building Research Institute: Integrated Technological Development Project: Report on the Development of Evaluation Technology for Fire-protection and Fire-resistant Performances, No. 9-3, The Building Center of Japan, 1998 (in Japanese)

29. Richard D. Peacock, Walter W. Jones and Richard W. Bukowski: Verification of Model of Fire and Smoke Transport, Fire Safety Journal, Vol.21, 1993

30. John A. Rockett, Masahiro Morita and Leonard Y. Cooper: Comparisons of NBS/Harvard VI Simulations and Data from All Runs of a Full-scale Multi-room Fire Test Program, 1989

31. Toshio Yamana, Takeyoshi Tanaka: Smoke Control in Large Scale Spaces, Fire Science and Technology, Vol.5 (1), Science University of Tokyo 1985

32. Takeyoshi Tanaka, Toshio Yamana, and Kazuto Nakamura: Full Size Experiment on Smoke Ventilation at the Pavilion at the Science and Technology Exposition, 
Building Research Institute, Ministry of Construction, 1986 (in Japanese)

33. Bjorn Karlson and James G. Quintiere: Enclosure Fire Dynamics, CRC Press, 1999

34. Johan Lundin: Uncertainty in Smoke Transport Models, Swedish Fire Research Board (BRANDFORSK), 1997

35. Edited by Ministry of Construction Integrated Technological Development Project: Report on the Development of Fire Safety Design Method for Buildings (Development of Design Method of Smoke Control and Evacuation), 1986 (in Japanese)

36. Ken Matsuyama, Masayuki Mizuno Takao Wakamatsu, Kazunori Harada, "A Systematic Experiments of Room and Corridor Smoke Filling for Use in Calibration of Zone and CFD Fire Models for Engineering Fire Safety Design of Buildings", Fire Science and technology, Vol. 21(1), pp. 43-55, Science University of Tokyo, 2001

37. Masahiro Ichikawa: Structural Reliability Engineering -- Reliability Method of Strength Design and Life Predict --, Kaibundo, 1988 (in Japanese)

38. Edited by The Building Center of Japan: New Guide to Building Fire Protection Plan, pp.45, 1995 (in Japanese)

39. Edited by The Architectural Institute of Japan: 2nd Edition, Compact Architectural Design Corpus, Maruzen, 1995 (in Japanese)

40. Edited by Shimizu Corporation: Architectural Plan and Design Series 37, New Office Building, Ichigaya Publishing, 2000 (in Japanese)

41. Edited by Nikken Sekkei Ltd.: Architectural Plan and Design Series 38, New High-rise Office Building, Ichigaya Publishing, 2000 (in Japanese)

42. Edited by The Architectural Institute of Japan: Architectural Design Corpus 8, Architecture -- Industry, Maruzen, 1981 (in Japanese)

43. Edited by The Architectural Institute of Japan: Architectural Design Corpus 3, Maruzen, 1974 (in Japanese)

44. Shinkenchiku 11, Shinkenchiku-sha, 1998 (in Japanese)

45. Edited by The Building Center of Japan: New Guide to Smoke Ventilation Equipment Technology, 1987 Edition (in Japanese)

46. Mina Nakano and Ichiro Hagiwara: Consideration on the Establishment of Egress Start Time Used for the Verification of Egress Safety Performance, Nihon Kenchiku Gakkai Taikai Kogaishu, Fire Prevention, pp.97-100, Sep. 2001 (in Japanese)

47. Frantzich, H., Reaction Times Prior to Evacuation for Shops, Restaurants and Public Dance-Halls, LUTVDG/TVBB 3071 SE, Department of Fire Safety Engineering, Lund University, 1993 